\title{
Vitamin B6 deficient plants display increased sensitivity to high light and photo-oxidative stress Michel Havaux*1,2,3, Brigitte Ksas ${ }^{1,2,3}$, Agnieszka Szewczyk ${ }^{4}$, Dominique Rumeau ${ }^{1,2,3}$, Fabrice Franck ${ }^{5}$, Stefano Caffarri ${ }^{1,2,3}$ and Christian Triantaphylidès $1,2,3$
}

Address: ${ }^{1}$ Commissariat à l'Energie Atomique (CEA), Institut de Biologie Environnementale et de Biotechnologie, Laboratoire d'Ecophysiologie Moléculaire des Plantes, 13108 Saint-Paul-lez-Durance, France, ${ }^{2}$ Centre National de la Recherche Scientifique (CNRS), Unité Mixte de Recherche Biologie Végétale et Microbiologie Environnementales, 13108 Saint-Paul-lez-Durance, France, ${ }^{3}$ Université Aix-Marseille, 13108 Saint-Paul-lezDurance, France, ${ }^{4}$ Pharmaceutical Faculty of the Collegium Medicum, Jagiellonian University, Krakow, Poland and ${ }^{5}$ Laboratory of Plant Biochemistry and Photobiology, Institute of Plant Biology, University of Liège, 4000-Liège, Belgium

Email: Michel Havaux* - michel.havaux@cea.fr; Brigitte Ksas - brigitte.ksas@cea.fr; Agnieszka Szewczyk - agniszew@yahoo.com; Dominique Rumeau - dominique.rumeau@cea.fr; Fabrice Franck - F.Franck@ulg.ac.be; Stefano Caffarri - stefano.caffarri@univmed.fr; Christian Triantaphylidès - ctriantaphylid@cea.fr

* Corresponding author

Published: 10 November 2009

BMC Plant Biology 2009, 9:130 doi:10.1 I86/147I-2229-9-130
Received: 7 July 2009

Accepted: 10 November 2009

This article is available from: http://www.biomedcentral.com//47/-2229/9//30

(c) 2009 Havaux et al; licensee BioMed Central Ltd.

This is an Open Access article distributed under the terms of the Creative Commons Attribution License (http://creativecommons.org/licenses/by/2.0), which permits unrestricted use, distribution, and reproduction in any medium, provided the original work is properly cited.

\begin{abstract}
Background: Vitamin B6 is a collective term for a group of six interconvertible compounds: pyridoxine, pyridoxal, pyridoxamine and their phosphorylated derivatives. Vitamin B6 plays essential roles as a cofactor in a range of biochemical reactions. In addition, vitamin B6 is able to quench reactive oxygen species in vitro, and exogenously applied vitamin $B 6$ protects plant cells against cell death induced by singlet oxygen $\left({ }^{\prime} \mathrm{O}_{2}\right)$. These results raise the important question as to whether plants employ vitamin B6 as an antioxidant to protect themselves against reactive oxygen species.

Results: The pdxI.3 mutation affects the vitamin B6 biosynthesis enzyme, pyridoxal synthase (PDXI), and leads to a reduction of the vitamin B6 concentration in Arabidopsis thaliana leaves. Although leaves of the $p d x I .3$ Arabidopsis mutant contained less chlorophyll than wild-type leaves, we found that vitamin B6 deficiency did not significantly impact photosynthetic performance or shoot and root growth. Chlorophyll loss was associated with an increase in the chlorophyll $a / b$ ratio and a selective decrease in the abundance of several PSIl antenna proteins (Lhcbl/2, Lhcb6). These changes were strongly dependent on light intensity, with high light amplifying the difference between $p d x I .3$ and the wild type. When leaf discs were exposed to exogenous ' $\mathrm{O}_{2}$, lipid peroxidation in $p d x I .3$ was increased relative to the wild type; this effect was not observed with superoxide or hydrogen peroxide. When leaf discs or whole plants were exposed to excess light energy, $1 \mathrm{O}_{2}$-mediated lipid peroxidation was enhanced in leaves of the $p d x I .3$ mutant relative to the wild type. High light also caused an increased level of ${ }^{\prime} \mathrm{O}_{2}$ in vitamin B6-deficient leaves. Combining the $p d x I .3$ mutation with mutations affecting the level of 'classical' quenchers of ${ }^{\prime} \mathrm{O}_{2}$ (zeaxanthin, tocopherols) resulted in a highly photosensitive phenotype.

Conclusion: This study demonstrates that vitamin B6 has a function in the in vivo antioxidant defense of plants. Thus, the antioxidant activity of vitamin B6 inferred from in vitro studies is confirmed in planta. Together with the finding that chloroplasts contain vitamin B6 compounds, the data show that vitamin B6 functions as a photoprotector that limits ${ }^{1} \mathrm{O}_{2}$ accumulation in high light and prevents ${ }^{\prime} \mathrm{O}_{2}$-mediated oxidative damage.
\end{abstract}




\section{Background}

Natural vitamin B6 consists of six interconvertible compounds, pyridoxine, pyridoxal, pyridoxamine and their phosphorylated derivatives, pyridoxine 5'-phosphate, pyridoxal 5'-phosphate and pyridoxamine 5'-phosphate [1-3]. Most bacteria, fungi and plants possess vitamin B6 biosynthesis pathways, but mammals must acquire the vitamin in their diet. In plants, the de novo pathway of vitamin B6 biosynthesis relies on two proteins, PDX1 and PDX2, which function as a glutamine amidotransferase and produce pyridoxal-phosphate from intermediates of glycolysis and the pentose phosphate pathway [4,5]. PDX1 and PDX2 work together, with the latter protein as the glutaminase and the former as the synthase domain.

Vitamin B6 plays essential roles as a cofactor in a wide range of biochemical reactions, predominantly in amino acid metabolism [6,7]. Recently, besides their classical role as coenzymes, a new function has emerged for the various vitamin B6 compounds in cellular antioxidant defense. A link between vitamin B6 and oxidative stress was originally established in the phytopathogenic fungus Cercospora nicotianae. Mutant strains were identified that were particularly vulnerable to their own toxin cercosporin, a photosensitizer that produces singlet oxygen $\left({ }^{1} \mathrm{O}_{2}\right)$ in the light [8]. Unexpectedly, cloning of the mutant genes in $C$. nicotianae revealed that the mutated fungi were affected in a gene of the vitamin B6 biosynthesis pathway [9]. Subsequently, it was shown in vitro that vitamin B6 is able to quench ${ }^{1} \mathrm{O}_{2}$ with a high efficiency $[9,10]$. Additional analyses revealed that vitamin B6 is also able to quench superoxide [11]. The antioxidant capacities of vitamin B6 were confirmed in yeast or animal cell cultures supplied with exogenous vitamin B6 compounds and exposed to different oxidative treatments [12-16]. Similarly, exogenously applied vitamin B6 was found to protect plant protoplasts against ${ }^{1} \mathrm{O}_{2}$-induced cell death [17]. These in vitro results indicate that vitamin $\mathrm{B} 6$ is a potential antioxidant and raise the question as to whether plants employ vitamin B6 to protect themselves against reactive oxygen species (ROS), particularly ${ }^{1} \mathrm{O}_{2}$. Several mutants of Arabidopsis thaliana defective in vitamin $\mathrm{B} 6$ biosynthesis have been recently isolated which could help answering this question. A knock out of the single PDX2 gene is lethal for Arabidopsis [4]. There are 3 homologues of PDX1 in Arabidopsis, PDX1.1, PDX1.2 and PDX1.3. Two of these (PDX1.1 and PDX1.3) have been shown to be functional in vitamin B6 synthesis [4]. While disruption of both genes causes lethality, the single mutants $p d x 1.1$ and $p d x 1.3$ are viable, indicating that one gene can compensate, at least partially, for the lack of the other. However, PDX1.3 is more highly expressed than PDX1.1, and a PDX1.3 knockout accumulates less vitamin B6 --about 30$40 \%$ of the wild type (WT) level) and has a more severe mutant phenotype in sterile medium [18-20]. Thus,
PDX1.3 appears to be more important for vitamin B6 synthesis than PDX1.1.

When grown in sterile medium in the absence of vitamin B6, seedlings of the $p d x 1.3$ mutant are strongly reduced in shoot growth and primary root growth $[18,19,21,22]$. Under these conditions, mutant seedlings were also found to be more sensitive to the ${ }^{1} \mathrm{O}_{2}$-generating dye Rose Bengal, to salt stress and to UV radiation relative to WT seedlings [21]. Although this is consistent with the idea that vitamin B6 could play a role in planta as an antioxidant, it is difficult to draw a definite conclusion because of the rather severe phenotype of the mutant in sterile culture. Interestingly, when grown on soil, the mutant phenotype of the $p d x 1.3$ mutant was much less pronounced. The reason for the less severe phenotype in soil is unknown. It has been suggested that there is a source of the vitamin in the soil [18]. However, the vitamin B6 concentration in the leaves of $p d x 1.3$ mutant plants grown on soil remains very low compared to WT $[19,20]$. Alternatively, it is possible that growth in sterile medium in a Petri dish represents a form of stress to which plants with low levels of vitamin $\mathrm{B} 6$ are more sensitive. In this study, we took advantage of the nearly normal development of the vitamin B6-deficient $p d x 1.3$ Arabidopsis mutant grown on soil to explore in detail the possibility that this vitamin functions as a photoprotector and an antioxidant in plants. We show that vitamin $\mathrm{B} 6$ acts as a new class of ${ }^{1} \mathrm{O}_{2}$ quencher, thereby protecting plants against photooxidative stress.

\section{Results \\ Growth and leaf chlorophyll content of pdx I plants}

Vitamin B6-deficient $p d x 1.3$ plants grown on soil (abbreviated as $p d x 1$ hereafter) looked similar to WT plants, except that young leaves in the center of the rosette were paler (Fig. 1A) as previously reported [18,21]. This was due to a decrease in photosynthetic pigments (Fig. 1B): both chlorophylls (Chl) and carotenoids were reduced by about $15-20 \%$, and this was accompanied by a significant increase in the Chl $a / b$ ratio. This reduction of the pigment content tended to disappear in mature, well developed mutant leaves. We also measured the concentration of various Chl precursors in young leaves (Fig. 1C). No significant change was observed in protochlorophyllide (PChlide) and chlorophyllide (Chlide) levels between WT and mutant leaves. In contrast, a decrease in the geranylgeranylated forms of $\mathrm{Chl}$, namely geranylgeranyl $\mathrm{Chl}$ (GG-Chl), dihydrogeranylgeranyl Chl (DHGG-Chl) and tetrahydrogeranylgeranyl Chl (THGG-Chl) was found in young leaves of the $p d x 1$ mutant. It is known from studies of etiolated seedlings that GG-Chl is formed through a preferential esterification of Chlide by geranylgeranyl disphosphate catalyzed by the enzyme Chl synthase [23-25]. GG-Chl is then reduced stepwise to Chl via DHGG-Chl and THGG-Chl by geranylgeranyl reductase [26]. There- 

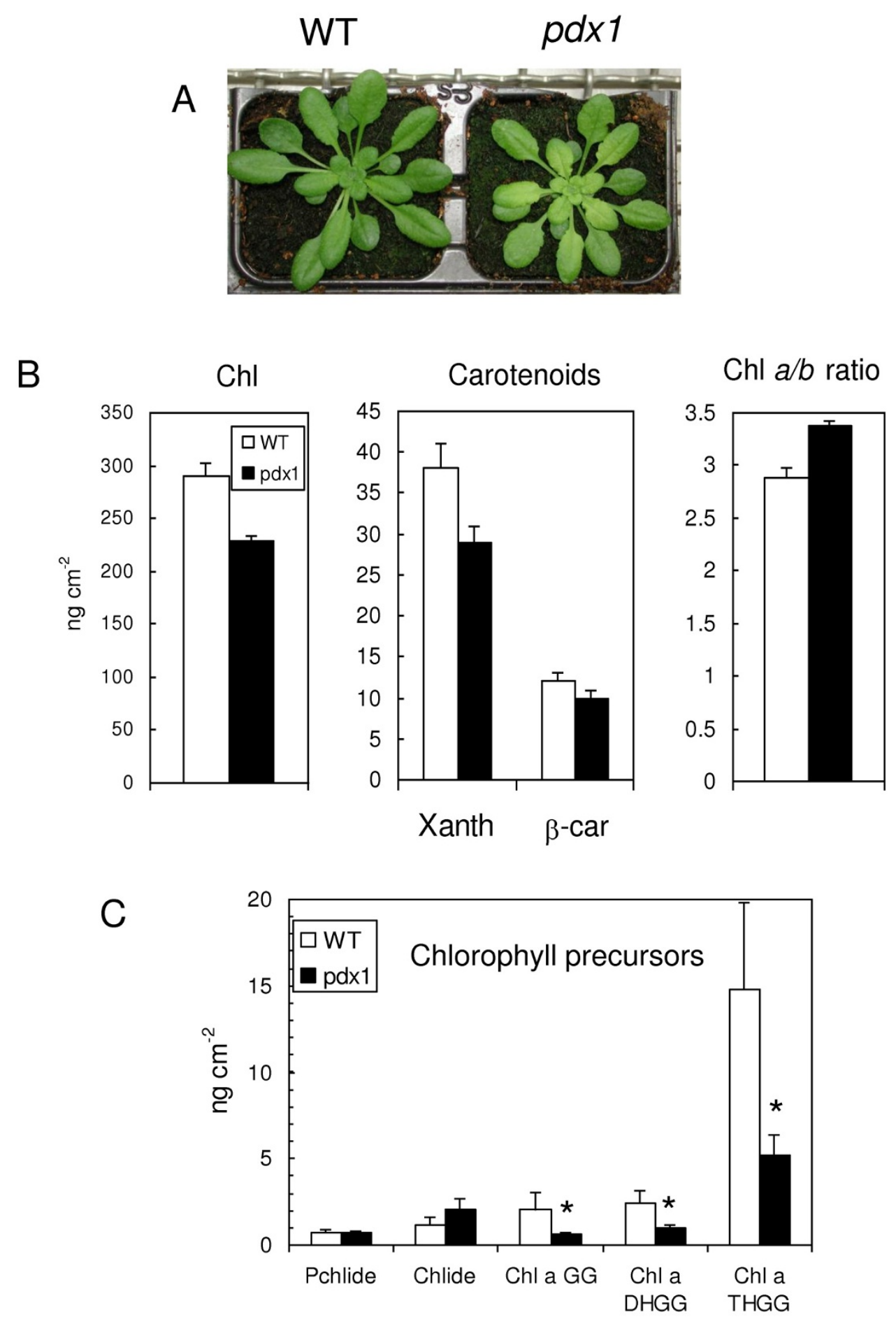

Figure I

Pigment content of young leaves of WT Arabidopsis and of the pdx I mutant. A) Plants aged 4 weeks. B) Chlorophyll and carotenoid content of young leaves. Chl, total chlorophyll; Xanth, xanthophylls; $\beta$-car, $\beta$-carotene. C) Level of various chlorophyll precursors in young leaves: Pchlide, protochlorophyllide; Chlide, chlorophyllide; GG-, DHGG- and THGG-Chl, geranylgeranyl-chlorophyll, dihydrogeranylgeranyl-chlorophyll and tetrahydrogeranylgeranyl-chlorophyll, respectively. Data are mean values of 4 measurements + SD. *, significantly different from the WT value with $P<0.01$ ( $t$ test). 
fore, the marked decrease in GG-Chl and other geranylgeranylated intermediates in leaves of the $p d x 1$ mutant suggests that the Chl synthase activity is somehow affected by the $p d x 1$ mutation, ultimately leading to a reduction in Chl concentration in the leaves. Therefore, it is likely that either the catalytic activity of Chl synthase itself is inhibited or that levels of the substrate geranylgeranyl diphosphate are more limiting. However, the unchanged level of tocopherols in the $p d x 1$ mutant (see below) would suggest that levels of geranylgeranyl phosphate are not limiting. Moreover, a rice mutant with impaired Chlide esterification by Chl synthase has a phenotype that strongly resembles $p d x 1$ mutants: decreased Chl levels were associated with an increased $\mathrm{Chl} a / b$ ratio in young plants, and these effects progressively disappeared as leaves matured [27]. We also found that the change in Chl content of leaves of the $p d x 1$ mutant relative to WT leaves was strongly dependent on light intensity (Fig. 2): the difference in Chl concentration and in the Chl $a / b$ ratio between WT and $p d x 1$ was strongly attenuated when plants were grown in low light $\left(80-100 \mu \mathrm{mol}\right.$ photons $\left.\mathrm{m}^{-2} \mathrm{~s}^{-1}\right)$ and was enhanced when plants were grown in high light (1000 $\mu \mathrm{mol} \mathrm{m} \mathrm{m}^{-2} \mathrm{~s}^{-1}$.

The decrease in photosynthetic pigments in leaves of the $p d x 1$ mutant was not associated with substantial changes

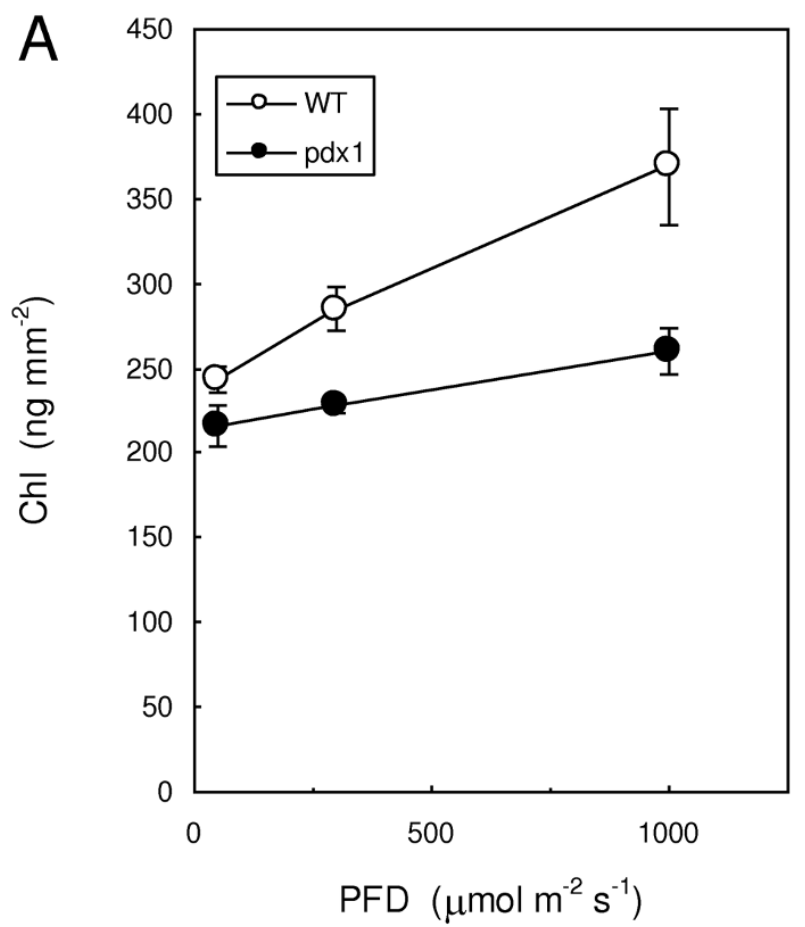

in photosynthetic electron transport. The quantum yield of linear electron transport measured by Chl fluorometry was comparable in WT and $p d x 1$ leaves (Fig. 3A). Similarly, the rate of $\mathrm{O}_{2}$ evolution measured with a Clark electrode did not appear to be affected by the $p d x 1$ mutation (Fig. 3B). Also, neither shoot growth or root growth were significantly affected by inactivation of the PDX1.3 gene (Additional File 1). Normal development of vitamin B6deficient shoot grown on soil was previously reported $[18,21]$. Clearly this was also the case for root development in soil.

We observed a difference in nonphotochemical energy quenching (NPQ) between WT leaves and leaves of the $p d x 1$ mutant, with NPQ being enhanced in the latter leaves, particularly at high photon flux densities (PFDs) above $500 \mu \mathrm{mol}$ photons $\mathrm{m}^{-2} \mathrm{~s}^{-1}$ (Fig. 3C). NPQ is a photoprotective mechanism that requires a transthylakoid $\mathrm{pH}$ gradient and the synthesis of zeaxanthin from violaxanthin in the light-harvesting antennae of PSII $[28,29]$. The increased NPQ in the $p d x 1$ mutant is thus consistent with the increased rate of photoconversion of violaxanthin to zeaxanthin: zeaxanthin synthesis in high light was faster, and the final extent of conversion was increased in the $p d x 1$ mutant relative to WT (Fig. 3D).

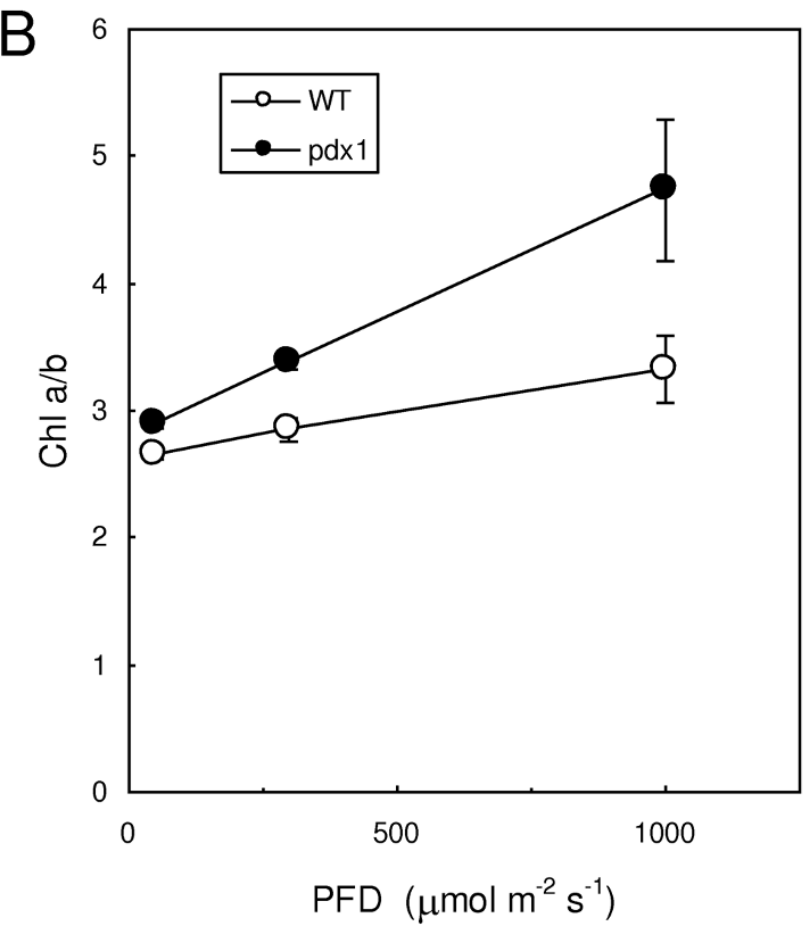

\section{Figure 2}

A) Chlorophyll content and B) chlorophyll a/b ratio in leaves of WT and $p d x I$ plants grown at different PFDs. Data are mean values of 3 measurements \pm SD. 

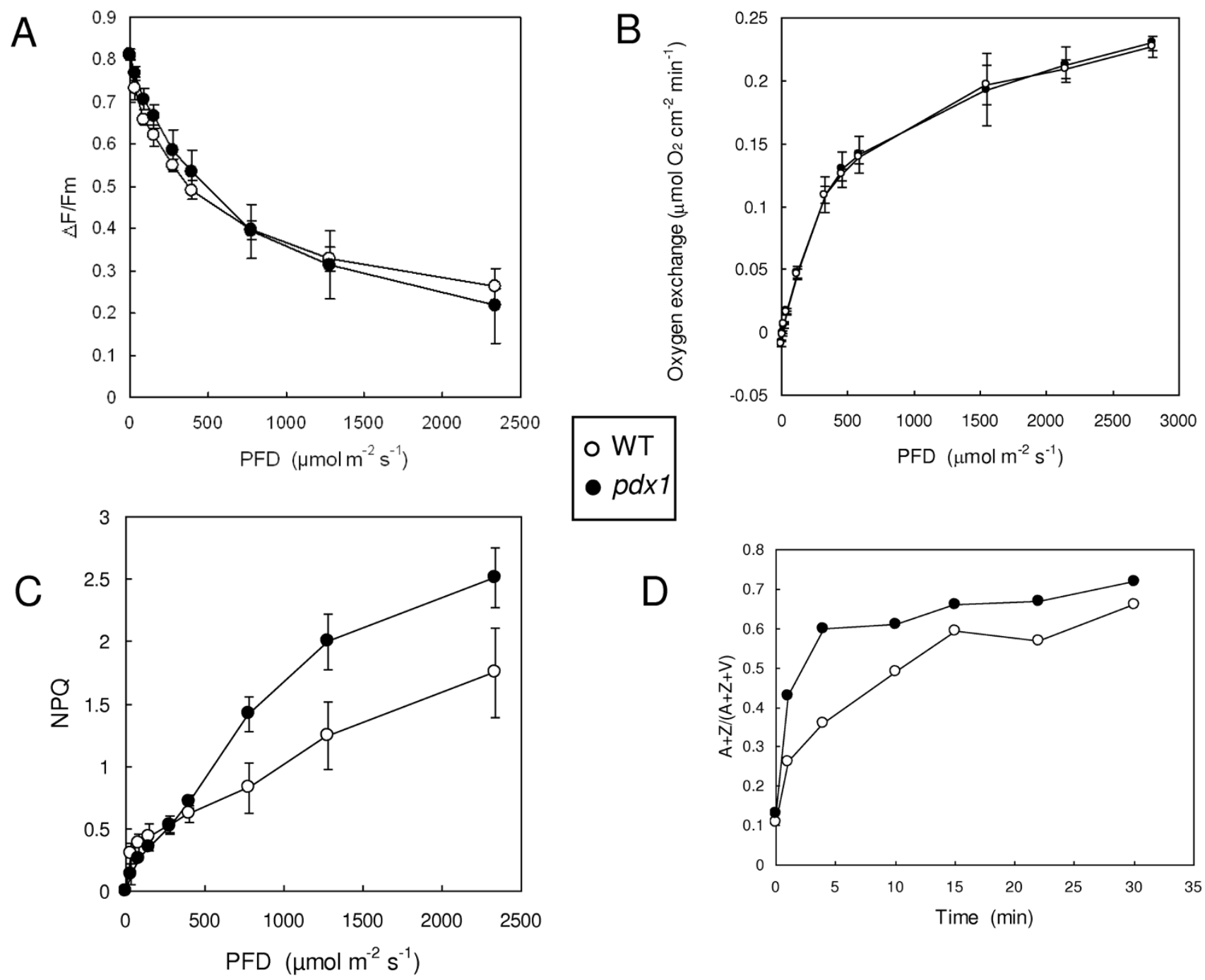

$p d \times 1$

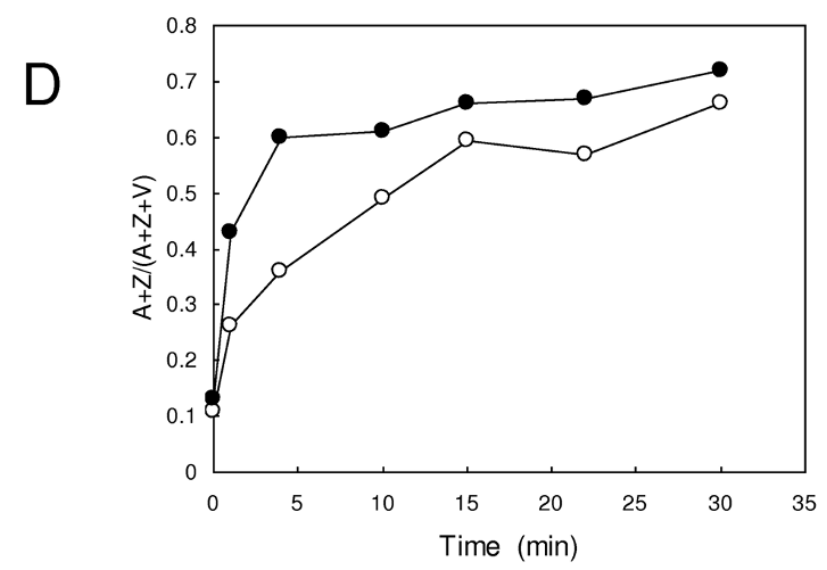

\section{Figure 3}

Photosynthetic parameters of WT Arabidopsis leaves and leaves of the pdx I mutant grown under control conditions ( $\left.150-200 \mu \mathrm{mol} \mathrm{m}^{-2} \mathrm{~s}^{-1}, 2^{\circ} \mathrm{C}\right)$. A) Quantum yield of PSIl photochemistry ( $\Delta \mathrm{F} / \mathrm{Fm}$ '), B) oxygen exchange and C) NPQ measured at different PFDs. Data are mean values of 3 or 4 measurements \pm SD. D) Light-induced conversion of violaxanthin $(V)$ into zeaxanthin $(Z)$ and antheraxanthin $(A)$, as calculated by the equation $(A+Z) /(V+A+Z)$. Zeaxanthin synthesis was induced by white light of PFD $1000 \mu \mathrm{mol} \mathrm{m} \mathrm{m}^{-2} \mathrm{~s}^{-1}$. Each point corresponds to a different leaf (I measurement per point).

\section{In vitro sensitivity of vitamin B6-deficient leaves to ROS} Leaf discs were exposed to eosin, a xanthene dye that generates ${ }^{1} \mathrm{O}_{2}$ in the light [30]. Illuminating leaf discs floating on a solution $(0.5 \%)$ of eosin has been previously shown to cause leaf photooxidation and lipid peroxidation [30,31]. We visualized the effect of eosin by autoluminescence imaging. This technique measures the faint light emitted by triplet carbonyls and ${ }^{1} \mathrm{O}_{2}$, the by-products of the slow and spontaneous decomposition of lipid hydroperoxides and endoperoxides [32-34]. Deactivation of excited carbonyls and ${ }^{1} \mathrm{O}_{2}$ produces photons (in the blue and red spectral regions, respectively) which can be recorded with a high-sensitivity, cooled CCD (charge coupled device) camera [34]. This technique has been used to map lipid peroxidation and oxidative stress in various biological materials including detached leaves [35], whole plants [36,37], animals [38] and humans [39]. As shown in Fig. 4A, ${ }^{1} \mathrm{O}_{2}$-induced lipid peroxidation was associated with a marked enhancement of leaf disc autoluminescence, as expected. Interestingly, the increase in autoluminescence was more pronounced in discs punched out from $p d x 1$ leaves than in WT discs (Fig. 4A). We quantified the autoluminescence intensity, and we found a $50 \%$-increase in the $p d x 1$ mutant relative to $\mathrm{WT}$ 

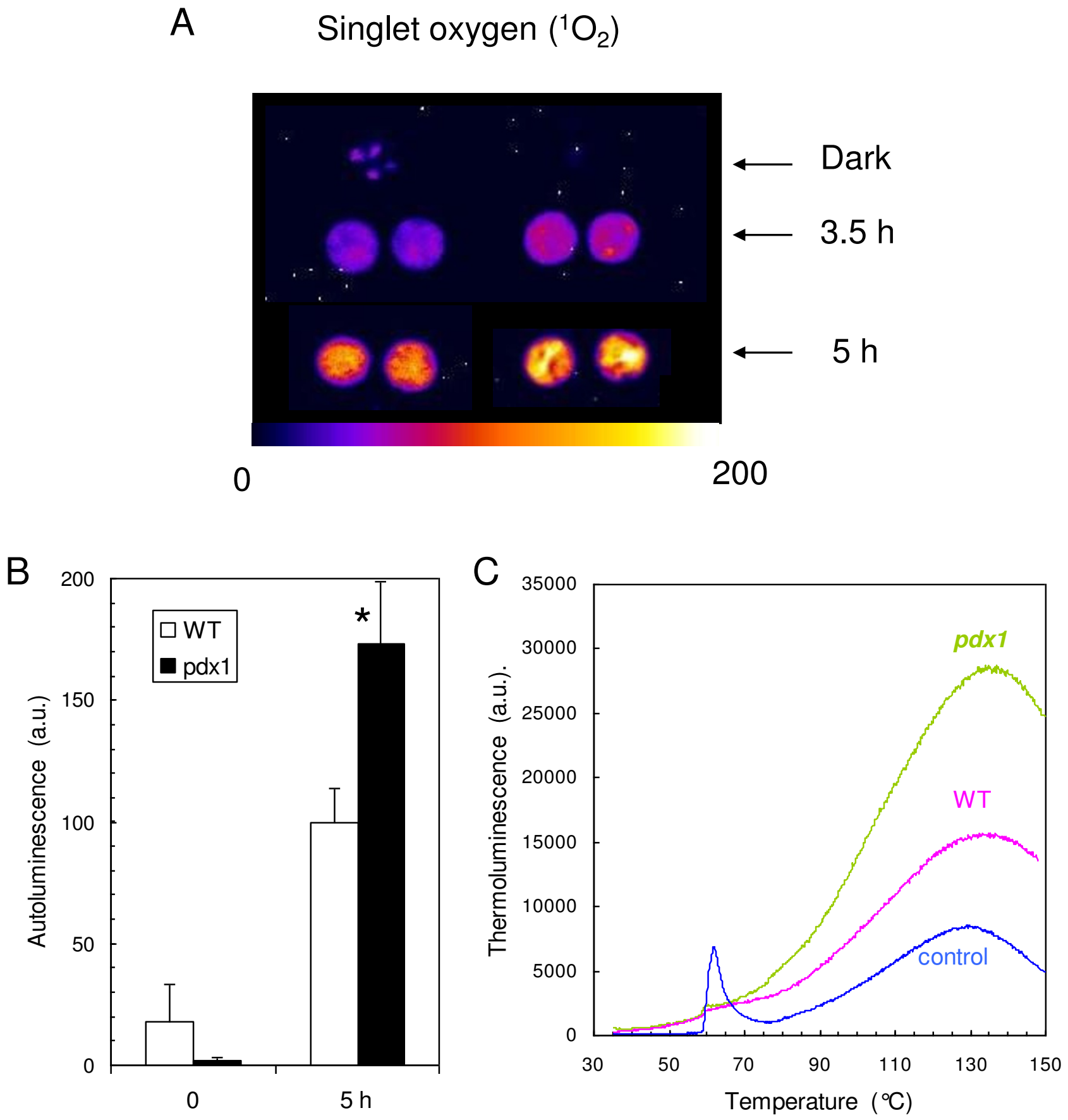

\section{Figure 4}

Oxidative stress in Arabidopsis leaf discs (WT and $p d x I$ ) exposed to the $1 \mathrm{O}_{2}$ generator eosin (0.5\%). A) Autoluminescence imaging of leaf discs exposed for $3.5 \mathrm{~h}$ or $5 \mathrm{~h}$ to eosin in the light $\left(400 \mu \mathrm{mol}\right.$ photons $\left.\mathrm{m}^{-2} \mathrm{~s}^{-1}\right)$. 'Dark' corresponds to eosin-infiltrated leaf discs kept in the dark for $5 \mathrm{~h}$. B) Autoluminescence intensity in leaf discs exposed for 0 or $5 \mathrm{~h}$ to eosin in the light. Data are mean values of 10 measurements $+S D$. *, significantly different from the WT value with $P<0.00 I$ ( $t$ test). C) Thermoluminescence band at high temperature (ca. $135^{\circ} \mathrm{C}$ ) in leaf discs exposed for $5 \mathrm{~h}$ to eosin in the light. Control, leaf discs from $p d x I$ kept in eosin in the dark. Control WT disks (not shown) was in the same thermoluminescence intensity range. The band peaking at ca. $60^{\circ} \mathrm{C}$ in the control is typical of Arabidopsis. Its origin is unknown; it is not related to lipid peroxidation and could be due to thermolysis of a (yet unidentified) volatile compound [84]. 
(Fig. 4B). Thus, the $p d x 1$ mutant appeared to be more sensitive to ${ }^{1} \mathrm{O}_{2}$ toxicity than WT. This was confirmed by thermoluminescence analyses of lipid peroxidation (Fig. 4C). Thermal decomposition of lipid hydroperoxides is associated with photon emission in the $120-140^{\circ} \mathrm{C}$ range $[33,40]$. The amplitude of the thermoluminescence band peaking at $\sim 135^{\circ} \mathrm{C}$ has been correlated in previous studies with the extent of lipid peroxidation as measured biochemically $[33,36,41]$. The $135^{\circ} \mathrm{C}$ band amplitude was noticeably higher in eosin treated leaf discs taken from $p d x 1$ than from the WT. Using HPLC, we also found that the level of malondialdehyde, a 3-carbon aldehyde produced during lipid peroxidation, was $29 \%$ higher in $p d x 1$ leaf discs than in WT discs after the eosin treatment (3 repetitions, data not shown). Together these results show that eosin treatment results in significantly increased lipid peroxidation in the mutant.

In contrast to ${ }^{1} \mathrm{O}_{2}$, other ROS such as hydrogen peroxide and superoxide did not induce different amounts of photooxidation between mutant and WT leaf discs (Additional File 2). Although exposure of leaf discs to both ROS enhanced autoluminescence, this effect was similar in WT and $p d x 1$. Similarly, the $135^{\circ} \mathrm{C}$ thermoluminescence band of $p d x 1$ and WT leaf discs after $\mathrm{H}_{2} \mathrm{O}_{2}$ and superoxide treatment were indistinguishable (data not shown).

\section{Vitamin B6-deficient plants are more sensitive to $\mathbf{I} \mathbf{O}_{2}-$ mediated lipid peroxidation than WT leaves}

${ }^{1} \mathrm{O}_{2}$ was recently shown to be the major ROS involved in photooxidative damage to leaves [42]. A combination of low temperature and high light is known to be particularly favorable for inducing photooxidative stress in higherplant leaves [43]. Therefore, we exposed leaf discs to a high photon flux density (PFD) of $1000 \mu \mathrm{mol}$ photons $\mathrm{m}$ $2 \mathrm{~s}^{-1}$ at low temperature $\left(10^{\circ} \mathrm{C}\right)$. This treatment induced lipid peroxidation, as measured by autoluminescence (Fig. 5A) and thermoluminescence (Fig. 5B). Leaf discs from the $p d x 1$ mutant were clearly more sensitive to the high light treatment than WT discs: both signals were enhanced in the mutant compared to WT. When leaf discs taken from the $p d x 1$ mutant were infiltrated with vitamin B6 before the light treatment, the increased thermoluminescence relative to WT was lost, confirming that exogenous vitamin B6 can function as an antioxidant [17].

The high photosensitivity of vitamin B6-deficient leaf discs prompted us to investigate the responses of whole plants to photooxidative stress conditions. Figure 6 shows the effect of 2-d exposure of Arabidopsis plants to photooxidative stress induced by very high light $(1500 \mu \mathrm{mol}$ photons $\left.\mathrm{m}^{-2} \mathrm{~s}^{-1}\right)$ at low temperature $\left(6^{\circ} \mathrm{C}\right)$ on lipid peroxidation. Again, autoluminescence emission was much higher in $p d x 1$ than in WT after this treatment (Fig. 6A). This was particularly visible in the external leaves, in agreement with previous studies that have emphasized the higher sensitivity of mature leaves to oxidative stress relative to young, developing leaves [e.g. [31,44]]. This observation indicates that the increased sensitivity of $p d x 1$ to photooxidative stress is not directly attributable to the low-Chl phenotype of $p d x 1$ which was visible mainly in the young leaves.

The differential sensitivity of the $p d x 1$ mutant and WT to light stress was confirmed by thermoluminescence measurements (Fig. 6B) and also by HPLC analyses of lipid hydroperoxide concentrations (Fig. 6C). The level of HOTE (hydroxyl octadecatrienoic acid), the product of the oxidation of linolenic acid (the major fatty acid in plant leaves) doubled in WT plants after light stress. In $p d x 1$ the HOTE concentration increased by a factor of 5 . Figure 6D shows the relative proportions of the different HOTE isomers during lipid peroxidation induced by high light stress. Isomers specific to ${ }^{1} \mathrm{O}_{2}$ (10-HOTE and 15 HOTE, [45]) were present in high amounts, and their level relative to the isomers 9-HOTE and 16-HOTE, which are produced by all ROS (free radicals and ${ }^{1} \mathrm{O}_{2}$ ) was typical of ${ }^{1} \mathrm{O}_{2}$ attack on polyunsatured fatty acids (see [42]). Thus, one can conclude that $p d x 1$ plants are more sensitive to endogenous ${ }^{1} \mathrm{O}_{2}$ production than WT plants.

\section{${ }^{\prime} \mathrm{O}_{2}$ levels during illumination are enhanced in the $\mathrm{pdx} I$ mutant}

Singlet oxygen sensor green (SOSG) reagent is a fluorescein derivative compound that is selective to ${ }^{1} \mathrm{O}_{2}$ with no appreciable response to superoxide and hydroxyl radical [46]. In the presence of ${ }^{1} \mathrm{O}_{2}$, it emits a green fluorescence that peaks at $525 \mathrm{~nm}$. However, this fluorescent probe has a relatively low stability in the light, so that the use of this probe to measure ${ }^{1} \mathrm{O}_{2}$ production should be restricted to short illumination only. Figure 7A shows the fluorescence spectrum of Arabidopsis leaves infiltrated under pressure with SOSG and illuminated for $40 \mathrm{~min}$ at a PFD of 400 $\mu \mathrm{mol}$ photons $\mathrm{m}^{-2} \mathrm{~s}^{-1}$. SOSG fluorescence at $525 \mathrm{~nm}$ was well visible in the fluorescence emission spectrum of the illuminated leaves. This fluorescence was enhanced in $p d x 1$ relative to $W T$, indicating an increased level of ${ }^{1} \mathrm{O}_{2}$ in the former plants. Figure $7 \mathrm{~B}$ shows the fluorescence emission at $525 \mathrm{~nm}$ (F525) normalized to the fluorescence of chlorophylls at $680 \mathrm{~nm}$ (F680) in leaves infiltrated with SOSG, with vitamin $\mathrm{B} 6$ or with both. The only condition that caused a significant increase in the F525/F680 ratio, indicative of an increased production of ${ }^{1} \mathrm{O}_{2}$, was the illumination of SOSG-infiltrated leaves of the $p d x 1$ mutant. Interestingly, the photoinduced increase in the F525/F680 ratio of $p d x 1$ leaves was lost when leaves were infiltrated with vitamin B6 in addition to SOSG. This loss of SOSG fluorescence indicates that exogenous vitamin B6 can quench ${ }^{1} \mathrm{O}_{2}$ in vivo, thus confirming in vitro data [10]. 


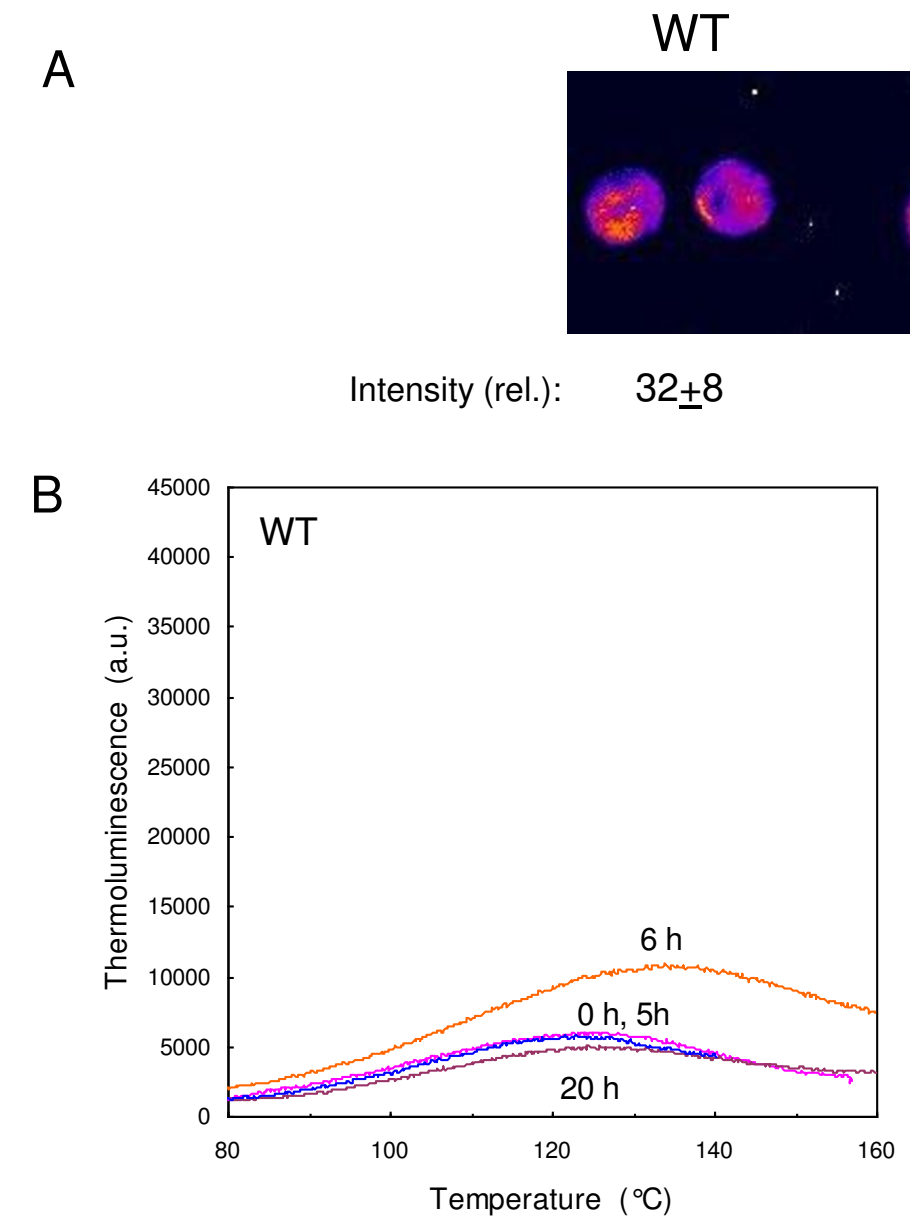

$p d x 1$

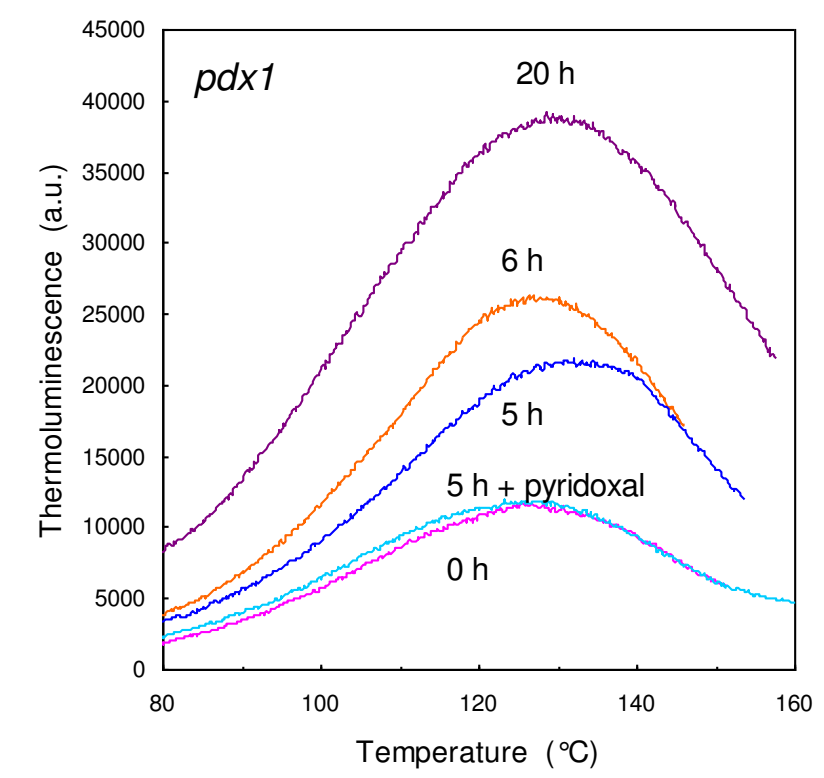

Figure 5

Photooxidative stress in leaf discs (WT and $p d x I$ ). A) Autoluminescence of leaf discs exposed for $6 \mathrm{~h}$ to $1500 \mu \mathrm{mol} \mathrm{m}^{-2}$ $\mathrm{s}^{-1}$ at $10^{\circ} \mathrm{C}$. B) Thermoluminescence band at high temperature $\left(\mathrm{ca} .135^{\circ} \mathrm{C}\right)$ in leaf discs exposed to high light stress for $0,5,6$ or $20 \mathrm{~h}$. The thermoluminescence signal of discs taken from leaves of the $p d x /$ mutant and preinfiltrated with vitamin B6 (2 mM) is also shown $(5 \mathrm{~h}+$ vitamin $B 6)$.

\section{The pdx I mutation enhances the photosensitivity of the vtel npq I mutant}

The vte1 npq1 double mutant is deficient in two major ${ }^{1} \mathrm{O}_{2}$ quenchers, vitamin E (tocopherols) and the carotenoid zeaxanthin [47]. Vte1 npq1 is photosensitive, exhibiting oxidative stress and lipid peroxidation in high light $[42,47]$. This is illustrated in Fig. 8 where vte 1 npq1 plants were exposed to a rather moderate light stress (white light of PFD $1000 \mu \mathrm{mol} \mathrm{m} \mathrm{m}^{-2} \mathrm{~s}^{-1}$ at $10^{\circ} \mathrm{C}$ ). This treatment brought about leaf bleaching (Fig. 8A) and increased autoluminescence (Fig. 8B). On the contrary, both WT and $p d x 1$ plants appeared to be resistant to this treatment. Similarly, the single mutants vte 1 and $n p q 1$ did not display symptoms of photooxidative damage under these conditions (data not shown). The vte1 npq1 mutant was crossed with the $p d x 1$ single mutant to generate a triple mutant (vte1 $n p q 1 p d x 1$ ) deficient in vitamins $\mathrm{E}$ and $\mathrm{B} 6$ and in zeaxanthin. The triple mutant exhibited an extreme sensitivity to high light: most leaves bleached (Fig. 8A) and leaf autoluminescence increased markedly (Fig. 8B). We also measured the HOTE concentration in leaves (Fig. 8C), which was higher in the triple mutant than in the double or single mutants. Thus, removing vitamin B6 in the vte 1 $n p q 1$ background led to a highly photosensitive phenotype. Analysis of the lipid peroxidation signature indicated that lipid peroxidation in the triple mutant was mediated by ${ }^{1} \mathrm{O}_{2}$ (Fig. 8D). The high photosensitivity of leaves of the vte1 $n p q 1 p d x 1$ triple mutant compared to leaves of the vte1 $n p q 1$ and $p d x 1$ mutants suggests that there is some overlap in the functions of vitamin B6 and the zeaxanthin-vitamin $\mathrm{E}$ duo. 


\section{A}
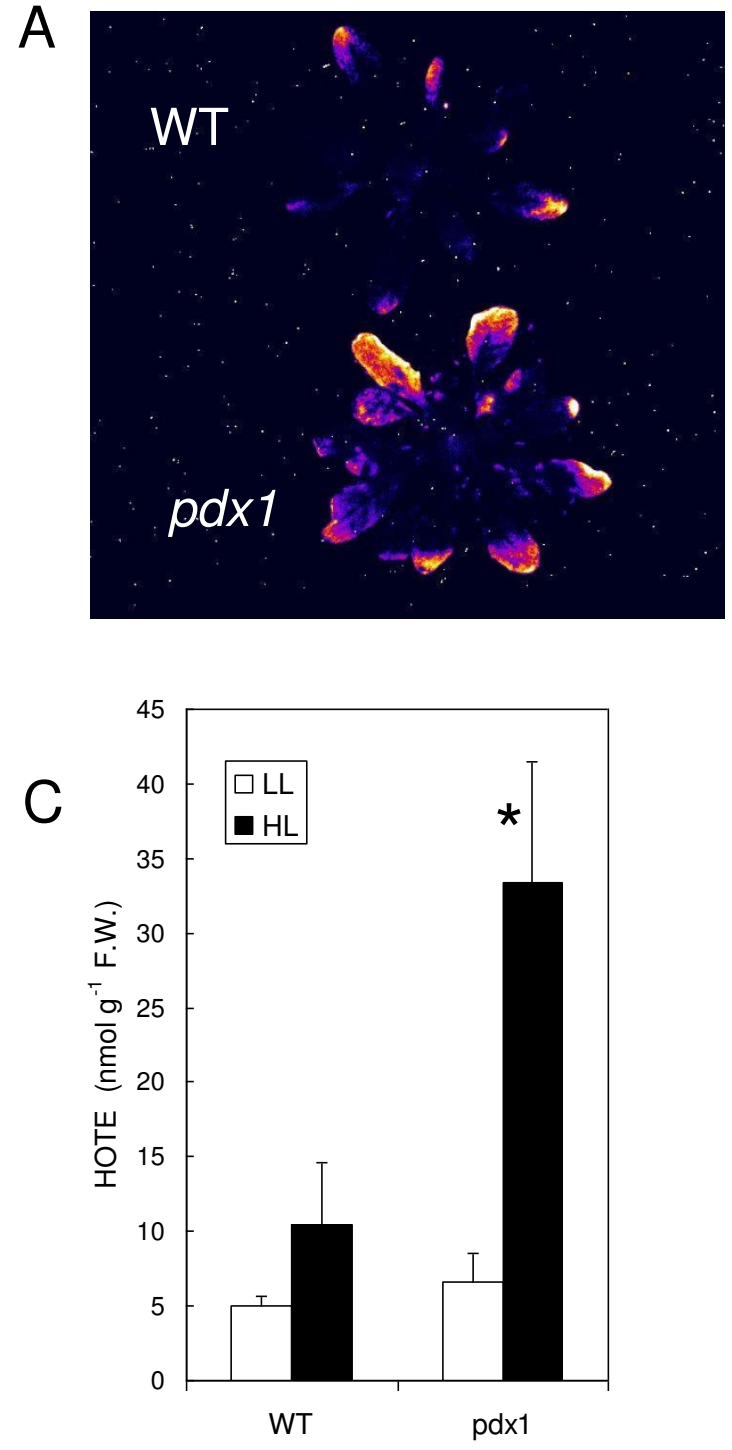

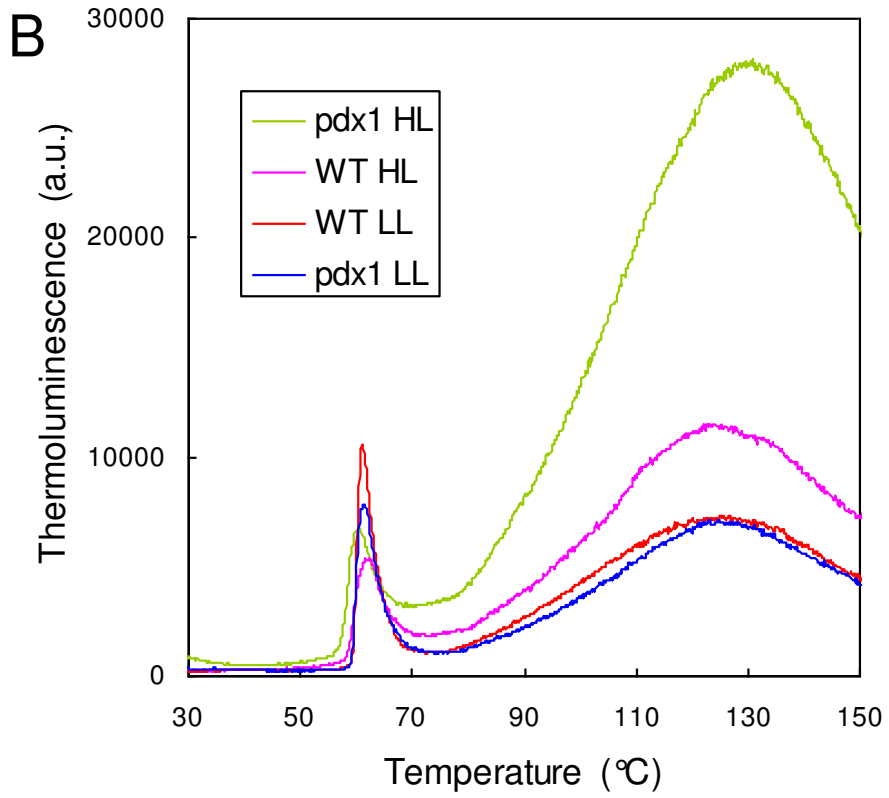

$\mathrm{D}$

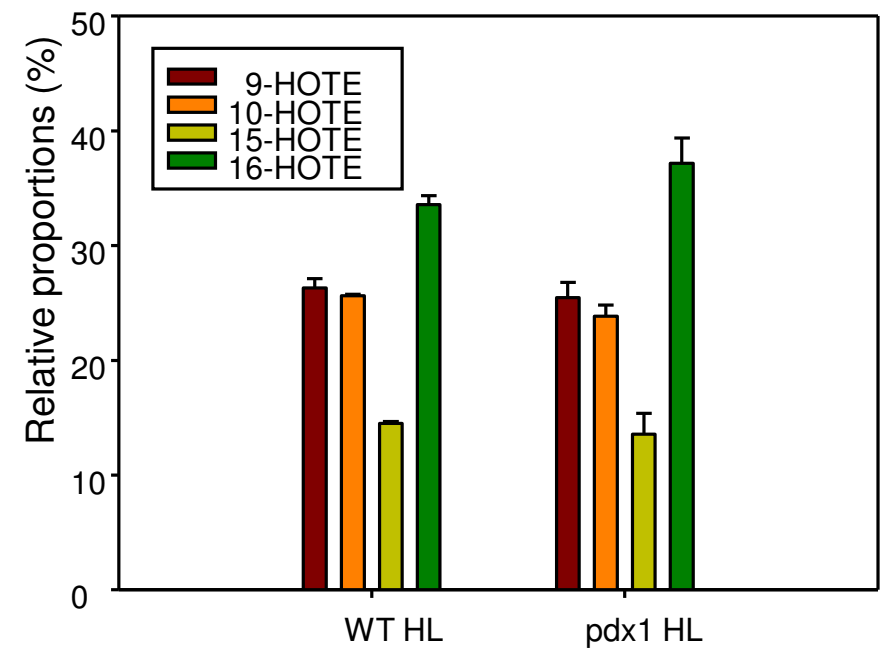

Figure 6

Photooxidative stress of whole Arabidopsis plants (WT and $p d x I$ ). A) Autoluminescence imaging of lipid peroxidation after high light stress $\left(2 \mathrm{~d}, 6^{\circ} \mathrm{C}, 1500 \mu \mathrm{mol} \mathrm{m} \mathrm{m}^{-2} \mathrm{~s}^{-1}\right)$. B) Thermoluminescence signal of WT leaves and leaves of the $p d x I$ mutant before and after high light stress (LL and HL, respectively). C) Lipid hydroperoxide level (HOTE) in leaves of control and high light-stressed WT and $p d x I$ plants. *, significantly different from the WT value with $P<0.015$ ( $t$ test). D) Distribution of lipid hydroperoxide (HOTE) isomers in leaves of control and high-light stressed WT and pdx I plants. Data are mean values of 3 to 5 measurements + SD.

\section{Protective mechanisms against ${ }^{\prime} \mathrm{O}_{2}$ in leaves of the pdx I mutant}

Figure 8 shows that $p d x 1$ plants are able to tolerate high light, provided the stress is not too severe. We analyzed the level of various antioxidant compounds in $p d x 1$ and WT plants during acclimation for 7 days to a PFD of 1000 $\mu \mathrm{mol} \mathrm{m} \mathrm{m}^{-2} \mathrm{~s}^{-1}$. Carotenoids and tocopherols are major quenchers of ${ }^{1} \mathrm{O}_{2}$ in plant leaves while ascorbate is one of the most efficient scavengers of ${ }^{1} \mathrm{O}_{2}$ [48]. Under control growth conditions, the ascorbate and tocopherol content of $p d x 1$ and WT plants was similar. Light acclimation led to a comparable increase in ascorbate, in WT and $p d x 1$ (Fig. 9A). Tocopherol was increased as well, but this change was less pronounced in $p d x 1$ (Fig. 9B). This could be due to the consumption of tocopherol by increased oxidative stress in the mutant. Although the total Chl level (on a leaf area basis) did not change during photoacclimation (Fig. 9C), the Chl $a / b$ ratio increased, especially in 

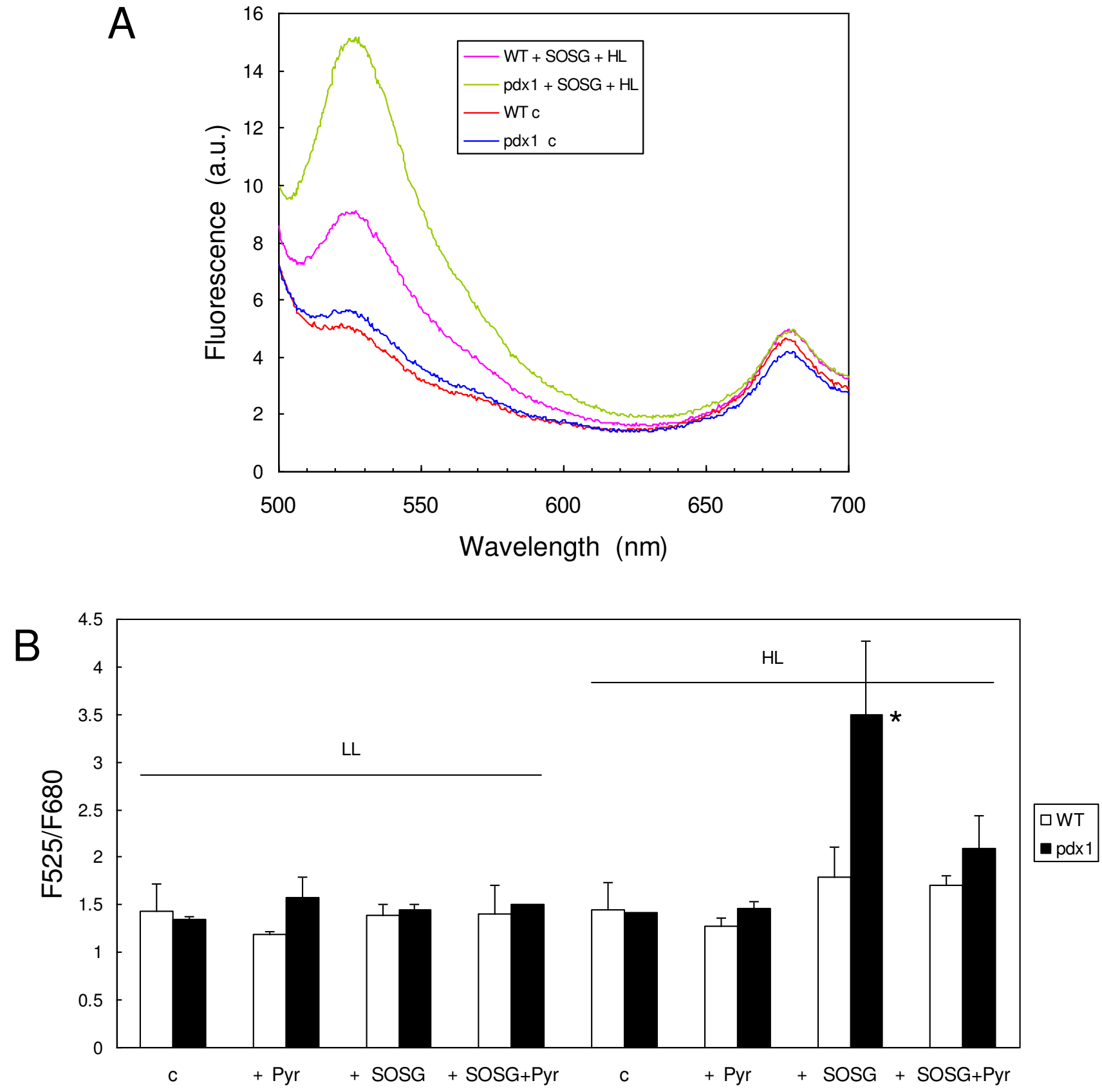

Figure 7

Fluorescence of SOGS in WT and mutant ( $p d x I)$ leaves exposed to high light. A) Fluorescence of leaves infiltrated with SOGS after exposure to white light $\left(\mathrm{HL}=450 \mu \mathrm{mol}\right.$ photon $\mathrm{m}^{-2} \mathrm{~s}^{-1}$ for $\left.40 \mathrm{~min}\right)$. Controls $(=c)$ were kept in dim light before fluorescence measurements. B) Fluorescence ratio F525/F680 of WT leaves and mutant leaves infiltrated with SOGS and/or vitamin B6 before or after illumination. Data are mean values of 3 measurements + SD. *, significantly different from the WT value with $P<0.025$ ( $\mathrm{t}$ test). 
\begin{tabular}{c|l}
$\mathrm{WT}$ & $p d x 1$ \\
\hline vte1 npq1 & vte1 npq1 pdx1
\end{tabular}
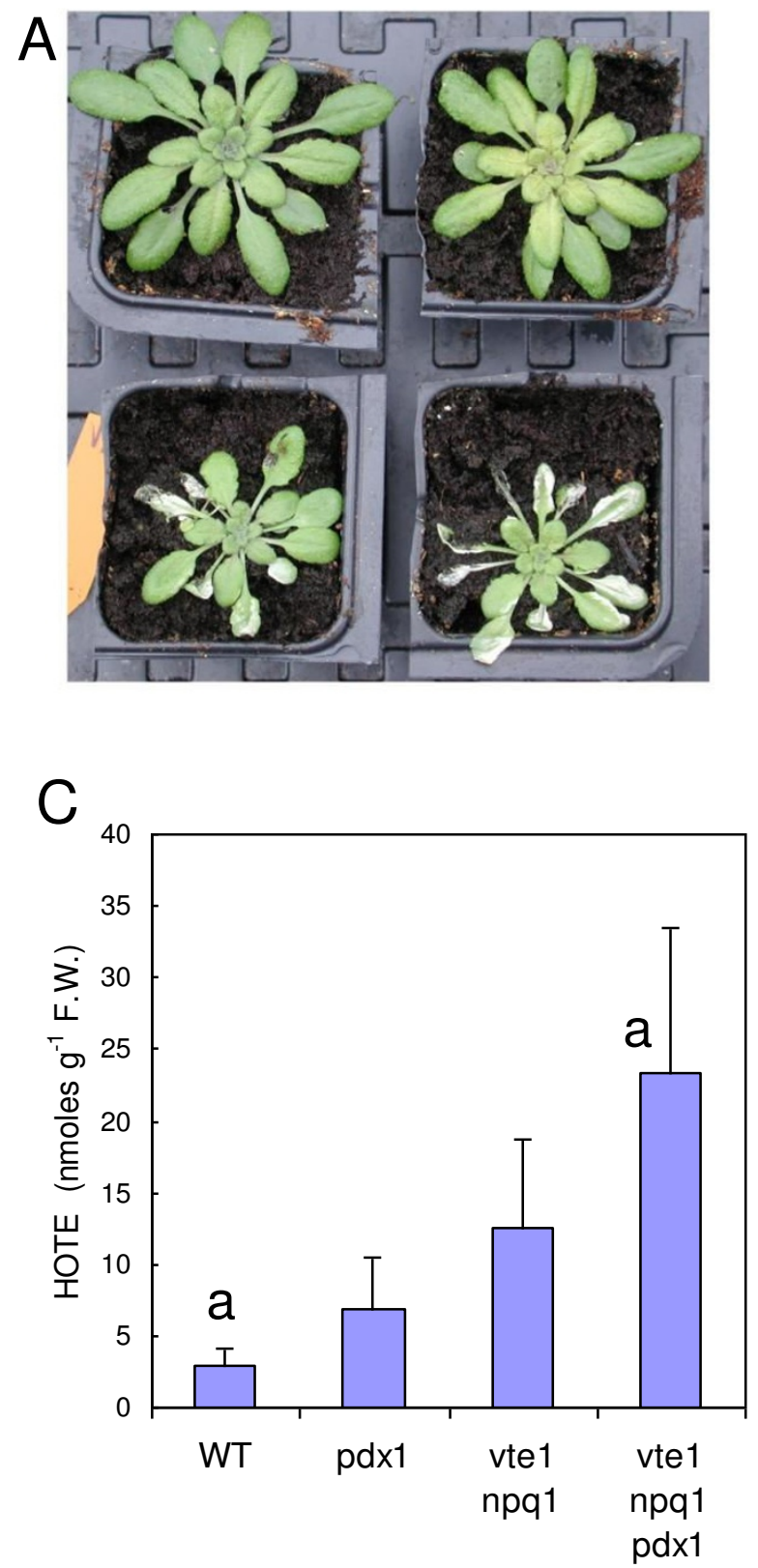

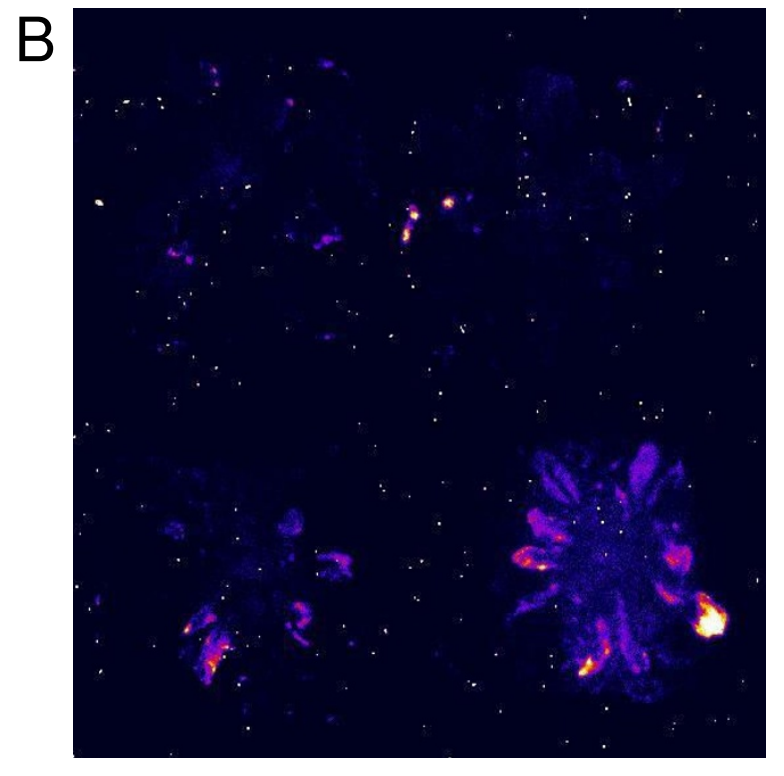

D

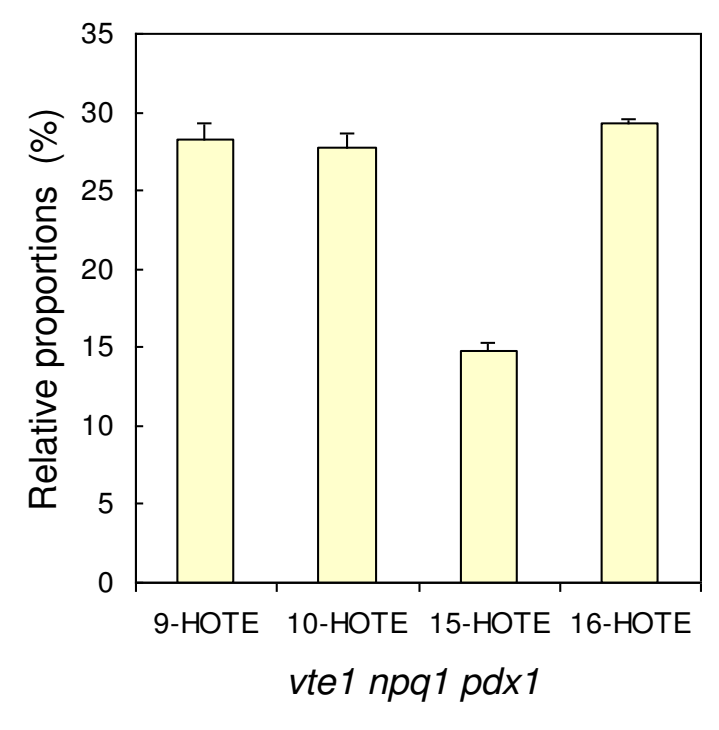

Figure 8

Effects of high light stress $\left(1000 \mu \mathrm{mol}\right.$ photons $\mathrm{m}^{-2} \mathrm{~s}^{-1}$ at $10^{\circ} \mathrm{C}$ for $2 \mathrm{~d}$ ) on WT plants and on pdx I, vte $\mathrm{l}$ npq $\mathrm{l}$ and vte I npq I pdx I mutant plants. A) Plants after the high light treatment. B) Autoluminescence imaging of lipid peroxidation. C) HOTE level. a, significantly different with $P<0.03$ ( $t$ test). D) Distribution of HOTE isomers in leaves of the vte $I n p q I p d x I$ triple mutant exposed to the high light treatment. Data are mean values of 3 or 4 measurements + SD. 


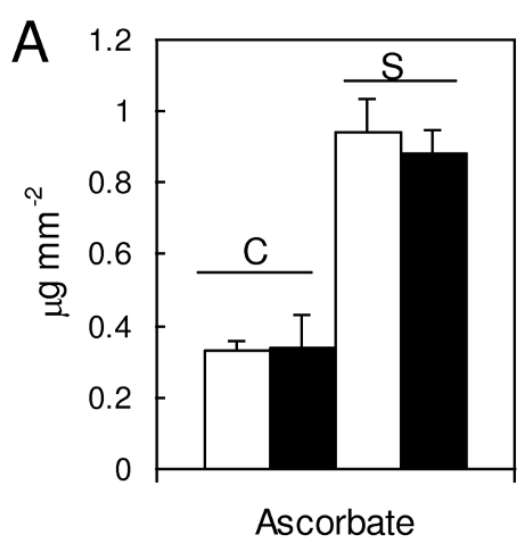

B
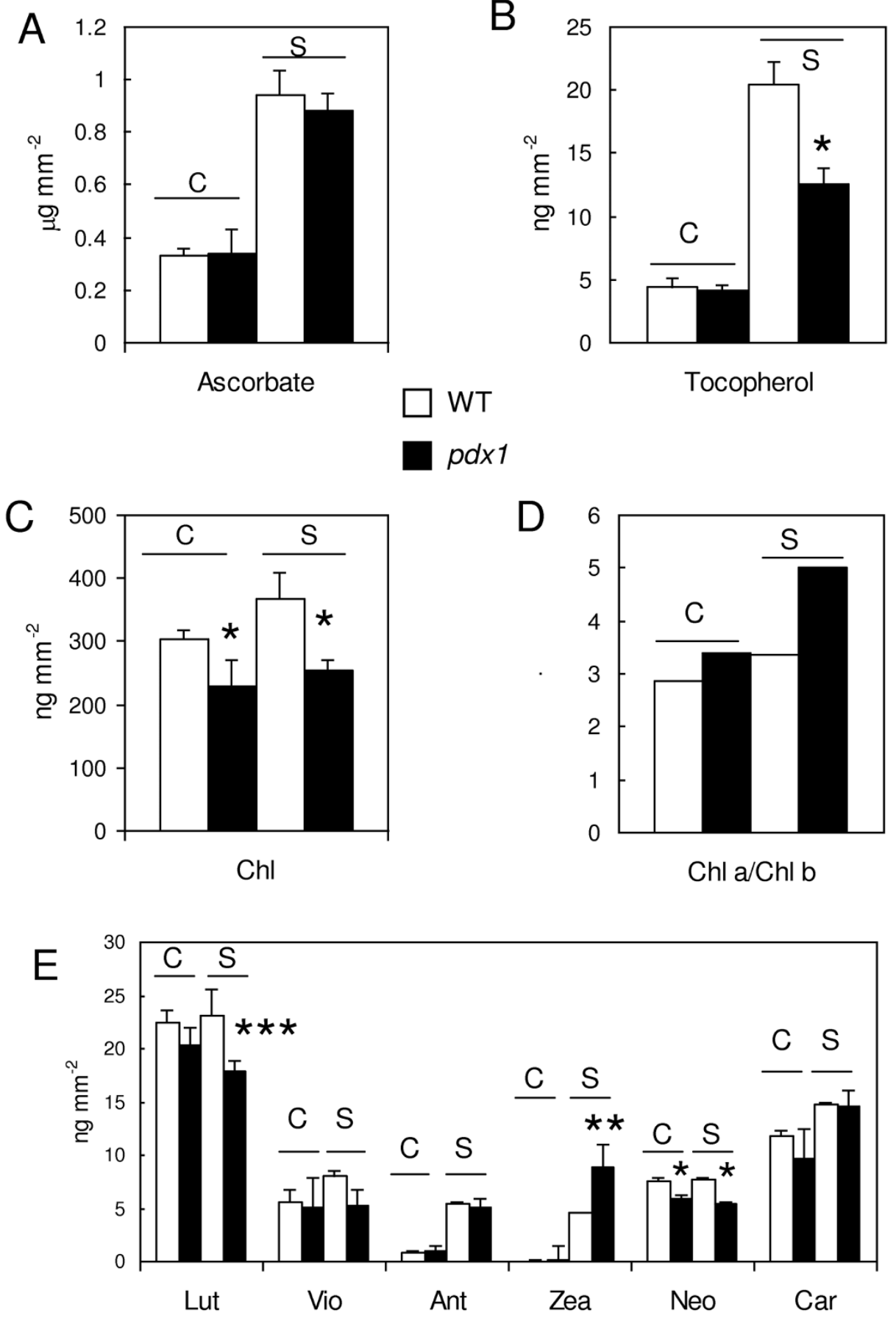

Figure 9

Levels of chlorophyll and various antioxidants in WT leaves and leaves of $p d x I$ after long-term exposure to high light ( $\left.1000 \mu \mathrm{mol} \mathrm{m}^{-2} \mathrm{~s}^{-1}, 10^{\circ} \mathrm{C}, 7 \mathrm{~d}\right)$. A) Ascorbate, B) $\alpha$-Tocopherol, C) Total chlorophyll, D) Chlorophyll a/b ratio, E) $\beta$-carotene (car) and xanthophylls (lutein (lut), violaxanthin (vio), antheraxanthin (ant), zeaxanthin (zea), neoxanthin (neo)). Data are mean values of 3 measurements $+S D . C=$ control plants; $S=$ plants exposed to the high light treatment. *, ** and ***, significantly different from the WT value with $P<0.001,0.035$ and 0.01 , respectively (t test). White bars, WT; black bars, $p d x I$ mutant. 
$p d x 1$ (Fig. 9D). The most obvious change in carotenoid composition was an accumulation of antheraxanthin and zeaxanthin, which was more pronounced in the $p d x 1$ mutant than in WT (Fig. 9E). $\beta$-Carotene also increased, but by a similar amount in $p d x 1$ and WT. Lutein and neoxanthin did not change significantly during photoacclimation although they were slightly reduced in the mutant compared with WT. This reduction reflects a decrease in the PSII antenna size in the mutant (see below). The Chlto-carotenoid ratio differed noticeably between WT and $p d x 1$, falling from 4.17 to 3.89 and from 3.93 to 2.76 respectively during high light acclimation. Accumulation of carotenoids, especially zeaxanthin, and the putative consumption of $\alpha$-tocopherol by oxidation suggests that the $p d x 1$ mutant senses a higher level of photostress than WT.

\section{PSII antenna size is decreased in leaves of the pdx I mutant} The decreased Chl levels and increased $\mathrm{Chl} a / b$ ratio of pxd1 mutants (particularly at high PFD, Fig. 2) suggest that there is a differential adjustment of the photosynthetic complexes to the light environment in mutant compared to WT plants. Therefore, we analyzed the relative abundance of Chl-containing photosynthetic complexes in thylakoids prepared from WT and $p d x 1$. The pigmented protein complexes of thylakoids were solubilized in $0.8 \%$ $\alpha$-dodecylmaltoside and were separated by ultracentrifugation on sucrose gradient (Fig. 10A). As expected, acclimation of WT leaves to high light $\left(1000 \mu \mathrm{mol} \mathrm{m}^{-2} \mathrm{~s}^{-1}\right)$ brought about a substantial decrease in the PSII antenna system (monomeric Lhcb and trimeric LHCII; B2 and B3 bands in Fig. 10A, respectively) relative to the PSII reaction center (B5 band). The PSI-LHCI supercomplex (B6 band) was also reduced during photoacclimation. Rather surprisingly the profile of thylakoids isolated from young leaves of low light-grown $p d x 1$ plants was very similar to the profile of high light-grown WT plants. High lightgrown $p d x 1$ leaves showed a rather extreme situation: the PSII antennae were strongly reduced compared to the PSII core and the abundance of PSI-LHCI supercomplexes was extremely low. Long-term acclimation of $p d x 1$ to high light was also associated with an increased level of free carotenoids (B1 band). Thus, the enhancement of the carotenoid/Chl ratio in leaves of the $p d x 1$ mutant seems to be largely due to unbound carotenoids. However, the quality of the separation of the photosynthetic complexes of thylakoids prepared from high light-acclimated leaves of $p d x 1$ was poor in $0.8 \% \alpha$-dodecylmaltoside, presumably because of a high lipid/protein ratio. Consequently, a higher $\alpha$-dodecylmaltoside concentration $(1.2 \%)$ was used to improve solubilization of thylakoids prepared from $p d x 1$ leaves after acclimation to high light (Fig. 10B). By comparison with low light-grown $p d x 1$ plants, the profile obtained with high-light treated $p d x 1$ at this detergent concentration confirmed that the effects of high light were drastic in the mutant, with a strong decrease in PSI-LHCI and PSII antenna size and an increase in the level of free pigments (Fig. 10B).

A global reduction of the PSII antenna system (gradient fractions B2 and B3 vs. B5) could explain the increase in the $\mathrm{Chl} a / b$ ratio in the $p d x 1$ mutant. However, the absorption spectra of the B2 and B3 bands showed that the lightharvesting complexes of PSII themselves contain less $\mathrm{Chl}$ $b$ (Additional File 3), suggesting that the composition of these bands was modified. This prompted us to analyze the protein composition of the different bands by SDSPAGE. Two different buffer systems were used: Tricine (Fig. 10C) and Laemmli-urea (Fig. 10D). The former system allows a good separation of the Lhcb polypeptides whereas the latter system is more appropriate for separating the Lhca proteins. In WT, acclimation to high light resulted in the decreased relative abundance of several PSII antennae (Lhcb1-2 and CP24, also named Lhcb6) and the increased relative abundance of CP26 (Lhcb5) with respect to control conditions. The abundance of CP29 (Lhcb4) was little affected (Fig. 10C). Low-light grown $p d x 1$ plants showed similar changes in the relative abundances of Lhcb1-2, CP24 and CP26 indicating that even under low light this mutant suffers light stress comparable to that of the WT at a PFD of $1000 \mu \mathrm{mol} \mathrm{m}^{-2} \mathrm{~s}^{-1}$. These changes were strongly amplified when $p d x 1$ was exposed to high light. Since CP26 and CP29 have a higher Chl $a / b$ ratio than other Lhcb antennae [49], the relative enhancement of these antennae might help contribute to the increased Chl $a / b$ ratio in $p d x 1$. The $\mathrm{Chl} a / b$ ratio of band B2 was particularly high (2.9) in $p d x 1$ plants grown under high light. Band B2 consists of a mixture of different monomeric antennae that usually have $\mathrm{Chl} a / b$ ratios between 1.2 and 3.0 [49]. Therefore the high $\mathrm{Chl} a / b$ ratio of the $\mathrm{B} 2$ band $p d x 1$ plants cannot simply be explained by a decrease in the abundance of the Chl $b$-rich monomers. Instead there must be an increased $\mathrm{Chl} a / b$ ratio within the Lhcb complex itself. This could be explained by either a reduced Chl $b$ availability as a result of stress that results in Chl $a$-rich folding of the Lhc complexes, or else by the preferential accumulation of specific Lhcb isoforms that are rich in Chl $a$, as previously suggested for maize [50]. We also observed a higher abundance of ATPase relative to antenna proteins under high light (Fig. 10C and 10D). However a precise quantification is not possible from these gels since ATPase fragments into several subcomplexes during gradient centrifugation, with the most intact complex migrating in $\mathrm{B} 6$ together with PSI. However, we were able to further confirm the higher abundance of ATPase relative to Chl-binding complexes by SDS-PAGE separation of total thylakoid proteins (data not shown).

Changes in the relative proportions of the Lhca proteins in response to high light and/or in $p d x 1$ were much less pro- 


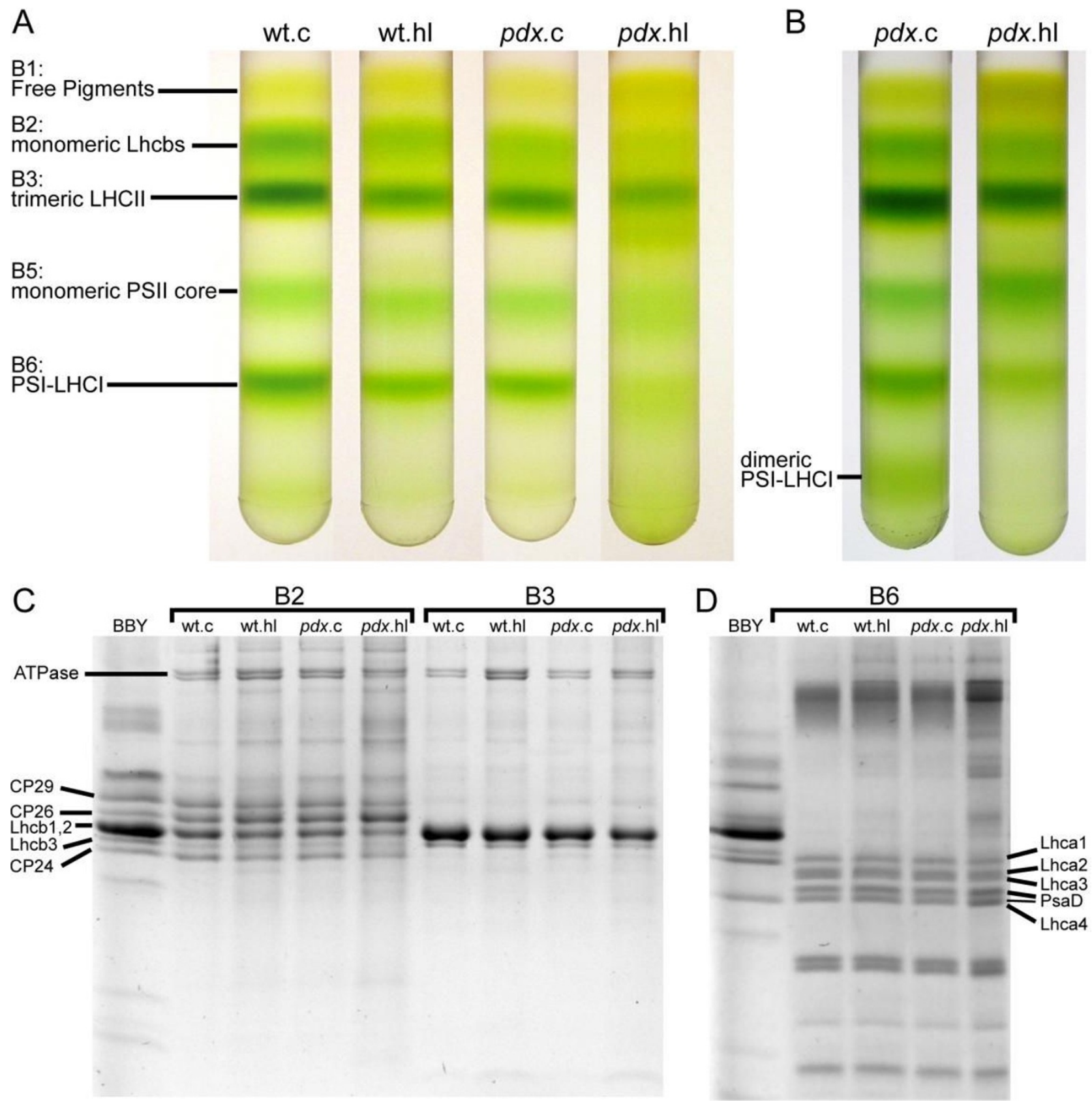

Figure 10

A) Separation of pigmented photosynthetic complexes of thylakoids prepared from leaves of WT and $p d x I$ by solubilization in $\mathbf{0 . 8 \%}$ dodecylmaltoside and ultracentrifugation on sucrose gradient. Thylakoids were prepared from leaves of WT and pdxI grown in low light (c, $200 \mu$ mol photons $\mathrm{m}^{-2} \mathrm{~s}^{-1}$ ) or acclimated for $7 \mathrm{~d}$ to high light (hl, $1000 \mu \mathrm{mol}$ $\mathrm{m}^{-2} \mathrm{~s}^{-1}$ ). BI, free pigments; B2, monomeric Lhcb antennae; B3, LHCll trimers; B5, PSII core (monomeric), B6, PSI-LHCl supercomplex. The B4 band (LHCll-CP29-CP24 supercomplex, see [85]) is not visible in this gradient. B) Ultracentrifugation gradient of thylakoids ( $p d x I, c$ and $\mathrm{hl}$ ) solubilized in $I .2 \%$ dodecylmaltoside. In the control $p d x I$ sample, an additional band appeared in the bottom of the gradient, which was hardly visible at $0.8 \%$ dodecylmaltoside and which corresponded to dimeric PSI-LHCI. This is presumably due to an artificial aggregation the high detergent concentration used in this preparation as previously found [86]; the same phenomenon was observed with WT thylakoids (data not shown). C and D) SDS-PAGE separation of the B2, B3 and B6 bands using two different buffer systems: tricine (C) and urea (D). See ref. [87] for identification of the bands. BBY = PSII-enriched membranes used as a reference for the PSII proteins. 
nounced than those occurring in the PSII antenna system (Fig. 10D). Nevertheless, a relative increase in PsaD and possibly Lhca 4 abundance seemed to occur in $p d x 1$ plants that had been acclimatised to high light (Fig. 10D).

Together, the data of Figs. 9 and 10 suggest that vitamin B6-deficient leaves sensed a higher level of light stress at a given PFD and over-reacted to increasing PFD compared to WT leaves. Incidentally, the smaller antenna system of $p d x 1$ was not associated with substantial changes in photosynthetic electron transport efficiency (Fig. 3). This is consistent with previous studies of PSII antenna mutants of Arabidopsis which have shown that rather strong reductions of the antenna system do not necessarily affect the photochemical activity of leaves [e.g. [51]].

\section{Vitamin B6 accumulation during high light acclimation} The expression of the PDX1 and PDX2 genes is up-regulated by several stress conditions, including high light $[11,18,52]$. However, so far the vitamin B6 concentration in plant tissues has not been measured under those conditions. Using HPLC, we were able to measure the nonphosphorylated forms of vitamin B6. Figure 11 shows the effect of high light $\left(1000 \mu \mathrm{mol}\right.$ photons $\mathrm{m}^{-2} \mathrm{~s}^{-1}$ at $10^{\circ} \mathrm{C}$ for $7 \mathrm{~d}$ ) on the concentration of nonphosphorylated vitamin B6 components of Arabidopsis leaves. Pyridoxine and pyridoxamine were the major vitamin $\mathrm{B} 6$ constituents measured in leaves, with pyridoxal being present in low amounts only. Pyridoxine and pyridoxal noticeably increased in high light while pyridoxamine did not change, so that the total (non-phosphorylated) vitamin B6 level increased by about $70 \%$.

\section{Discussion \\ Vitamin $\mathrm{B} 6$ deficiency leads to $1 \mathrm{O}_{2}$-mediated photodamage}

Vitamin B6-deficient Arabidopsis leaves were more sensitive to treatments with the ${ }^{1} \mathrm{O}_{2}$ generator eosin than WT leaves, and exogenous application of vitamin $\mathrm{B} 6$ reduced ${ }^{1} \mathrm{O}_{2}$ level and mitigated lipid peroxidation in leaf discs exposed to high light. The protective role of vitamin B6 observed in vitro was confirmed in vivo in Arabidopsis plants challenged with endogenous ${ }^{1} \mathrm{O}_{2}$ production induced by high light stress. Exposure of Arabidopsis plants to high light led to a rise in ${ }^{1} \mathrm{O}_{2}$ concentration and an accumulation of oxidized lipids, which were higher in $p d x 1$ than in WT. The increased level of lipid peroxidation in mutant leaves was attributable to a ${ }^{1} \mathrm{O}_{2}$ mediated attack on lipids. Those results show that vitamin B6 has a function in the protection of plants against ${ }^{1} \mathrm{O}_{2}$ toxicity and photooxidative stress. This confirms in vivo the antioxidant capacity of vitamin B6 previously inferred from in vitro studies [9-17]. The role of vitamin B6 in the response of plants to light stress was further supported by our observation that the concentration of this vitamin is increased in Arabidopsis leaves exposed to high light intensity. This finding is in line with previous studies that have shown an increased expression of genes of the vitamin B6 biosynthesis pathway (PDX1 and PDX2) by abiotic stresses $[11,18,52]$. Illumination of $p d x 1$ seedlings grown under sterile conditions has been reported to provoke degradation of the D1 protein of the PSII reaction center and to exacerbate the associated photoinhibition of PSII [18]. The latter phenomenon is attributed to ${ }^{1} \mathrm{O}_{2}$ attack on the D1 protein itself, triggering structural changes in the PSII centre that initiate proteolytic degradation of the protein [53]. These data add further support to our conclusions that reduced levels of vitamin B6 in $p d x 1$ leads to enhanced accumulation of ${ }^{1} \mathrm{O}_{2}$.

\section{Direct versus indirect effect of vitamin B6 in photoprotection}

The photoprotective role of vitamin $\mathrm{B} 6$ could be direct or indirect. A direct role would mean that vitamin B6 quenches ${ }^{1} \mathrm{O}_{2}$ produced by light in the chloroplasts. This is plausible because this vitamin is able to quench ${ }^{1} \mathrm{O}_{2}$ in vitro with a rather high efficiency [10]. The ${ }^{1} \mathrm{O}_{2}$ quenching rate constant of vitamin $\mathrm{B} 6$ is comparable to that of ascorbate and tocopherol [9]. However, because of the high reactivity of ${ }^{1} \mathrm{O}_{2}$, this supposes that vitamin $\mathrm{B} 6$ is present in planta in the vicinity of the ${ }^{1} \mathrm{O}_{2}$ production sites, namely the PSII reaction center and the chlorophyll antenna system in the chloroplasts [53]. Vitamin B6 levels in Arabidopsis leaves are relatively high ([20], this study), in the same range of concentrations as glutathione [48], but its sub-cellular distribution is unknown. To check if chloroplasts constitute a site of vitamin B6 accumulation in plant leaves, we prepared intact chloroplasts and we titrated vitamin B6 by HPLC (Additional File 4). Because our HPLC method requires large amounts of material (> $10 \mathrm{~g}$ of fresh weight), it was difficult to prepare sufficient amounts of intact chloroplasts from Arabidopsis leaves, and consequently we measured vitamin B6 in another plant species, tobacco, that is more suitable for purifying intact chloroplasts by ultracentrifugation on Percoll gradient. Both pyridoxine and pyridoxamine were detected in intact tobacco chloroplasts (Additional File 4). When normalized to the Chl content, the (nonphosphorylated) vitamin B6 content of chloroplasts $(\sim 0.16 \mu \mathrm{g} / \mathrm{mg} \mathrm{Chl})$ was approximately 3 times lower than the concentration in leaves. Considering that the chloroplast volume represents about $25 \%$ of the total cellular volume [54] and that $\mathrm{Chl}$ is localized exclusively in the chloroplasts, this suggests that there is a uniform distribution of vitamin B6 between the chloroplast and the rest of the cell. However, one cannot exclude that the level of vitamin B6 in chloroplasts was underestimated due to vitamin export during the chloroplast isolation. The occurrence of vitamin B6 in chloroplasts, as reported here, is consistent with a number of previous observations. First, the N-terminal amino 


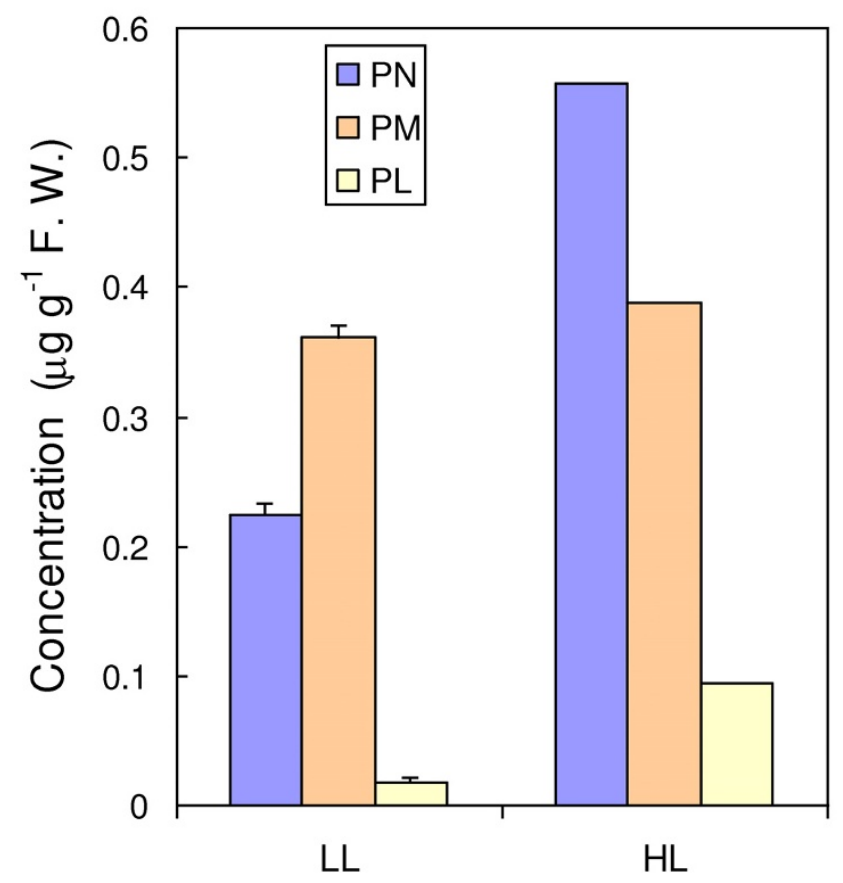

\section{Figure I I}

Vitamin B6 components (expressed in $\mu \mathrm{g} / \mathrm{g}$ fresh weight) in leaves of Arabidopsis plants grown in low light (LL) or acclimated for $7 \mathrm{~d}$ to high light (HL, $1000 \mu \mathrm{mol}$ photons $\mathrm{m}^{-2} \mathrm{~s}^{-1}$ at $\left.10^{\circ} \mathrm{C}\right)$. F. W. $=$ fresh weight. PM, pyridoxamine; PN, pyridoxine; PL, pyridoxal. Data are mean values of 2 or 3 measurements + SD.

acids of one of the enzymes of the vitamin B6 pathway, pyridoxine (pyridoxamine) 5'-phosphate oxidase, have been identified as a chloroplast transit peptide [55], suggesting a chloroplastic localization for this protein. Both components of the pyridoxal synthase complex, PDX1 and PDX2, have been shown to be attached to membranes, including chloroplastic membranes $[11,21]$. Furthermore, the present study has shown that vitamin $\mathrm{B} 6$ deficiency impacts the activity of $\mathrm{Chl}$ synthase, a plastidlocalized protein. Since vitamin B6 is an efficient quencher of ${ }^{1} \mathrm{O}_{2}$ in vitro, it is easy to speculate that the presence of a vitamin $\mathrm{B} 6$ pool in the chloroplast would reduce ${ }^{1} \mathrm{O}_{2}$ levels. However, under conditions of severe light stress, ${ }^{1} \mathrm{O}_{2}$ has been reported to leave thylakoid membranes and to migrate to the cytoplasm [56]. Therefore, since the light stress conditions used in this work to induce photooxidative damage were rather drastic (1500 $\mu$ mol photons $\mathrm{m}^{-2} \mathrm{~s}^{-1}$ at $6^{\circ} \mathrm{C}$ ), a leakage of ${ }^{1} \mathrm{O}_{2}$ from the chloroplast to the cytosol cannot be excluded and therefore an action of vitamin $\mathrm{B} 6$ within the cytosol is also possible.

Hydroperoxides and endoperoxides generated in lipid peroxidation are known to undergo fragmentation to pro- duce a broad range of reactive intermediates called reactive electrophile species $[57,58]$. Reactive electrophiles are harmful to macromolecules by reacting with nucleophilic groups, resulting in a variety of adducts and irreversible modifications. Compared to ROS, reactive electrophile species are stable and, due to their non-charged structure, some of them can migrate through hydrophobic membranes and hydrophilic media, so that they are able to propagate oxidative stress far from their site of formation [59]. Interestingly, pyridoxamine has been shown to trap lipid-derived carbonyl intermediates in vitro [60,61], and pyridoxamine adducts to lipid peroxidation products have been detected in the urine of pyridoxamine--treated animals [60]. In humans, pyridoxamine and pyridoxine are considered to be promising drug candidates for treatment of chronic conditions in which carbonyl compounds confer pathogenecity, such as diabetes $[62,63]$. A similar function as scavenger of intermediates in lipid peroxidation could be envisaged for vitamin $\mathrm{B} 6$ in plant cells. However, this mechanism does not explain the selective sensitivity of leaf discs to ${ }^{1} \mathrm{O}_{2}$ (Fig. 4 vs. Additional File 2) since free radical-induced lipid peroxidation also generates reactive carbonyl species. Moreover, we administrated 4-hydroxynonenal, one of the most toxic carbonyl compounds produced from lipid peroxides [58], to detached Arabidopsis leaves, using the procedure described by Mano et al. [64]. As expected, necrosis developed concentrically from the application site of the hydroxynonenal solution on the leaf, but the extent of necrosis was similar in WT leaves and leaves of the $p d x 1$ mutant (data not shown). Thus, vitamin B6 deficiency does not seem to enhance the sensitivity to reactive carbonyls, and an indirect function of vitamin B6 as scavenger of oxidized lipid derivatives seems unlikely.

One can also exclude the possibility that the increased level of ${ }^{1} \mathrm{O}_{2}$ in leaves of the $p d x 1$ mutant relative to WT leaves after illumination was due to an increased production of ${ }^{1} \mathrm{O}_{2}$ by the photosystems rather than a decreased quenching activity. In plants, ${ }^{1} \mathrm{O}_{2}$ is produced mainly from chlorophyll triplet states, which are formed when the balance between light absorption by the photosystems and light utilization by the photosynthetic processes is upset in favor of the former process. This can be excluded in leaves of the $p d x 1$ mutant since photosynthetic electron transport was not affected significantly relative to WT. Moreover, the total Chl concentration in $p d x 1$ was lowered by ca. $20 \%$, at least in young leaves, and this would be expected to reduce ${ }^{1} \mathrm{O}_{2}$ production $[65,66] .{ }^{1} \mathrm{O}_{2}$ can also be produced by $\mathrm{Chl}$ precursors such as Pchlide, as it is the case in the flu Arabidopsis mutant [67]. Based on our analyses of $\mathrm{Chl}$ biosynthesis intermediates, we can exclude this phenomenon in $p d x 1$. The fact that exogenously applied ${ }^{1} \mathrm{O}_{2}$ was more toxic to $p d x 1$ than to WT is another indication that a change in ${ }^{1} \mathrm{O}_{2}$ production by the 
photosystems cannot be the sole factor involved in the increased sensibility to ${ }^{1} \mathrm{O}_{2}$ damage in $p d x 1$. In this context, it is important to mention a recent work of Lytovchenko et al. [68] who showed that the profile of lipophilic compounds was not substantially affected in shoots of vitamin B6-deficient Arabidopsis plants. Therefore, we consider that the management of ${ }^{1} \mathrm{O}_{2}$ was less efficient in Arabidopsis leaves when vitamin B6 concentration was abnormally low.

The most efficient biological quenchers of ${ }^{1} \mathrm{O}_{2}$ are thought to be the carotenoids and the vitamins $\mathrm{C}$ and $\mathrm{E}$. Neither vitamin C (ascorbate) nor vitamin E (tocopherol) levels were reduced in $p d x 1$. Although the total carotenoid content (on a leaf area basis) was lowered, the carotenoid concentration normalized to the Chl content was enhanced in $p d x 1$. Among carotenoids, the xanthophyll zeaxanthin is known to play a crucial role in photoprotection $[28,29,36,69]$. Zeaxanthin synthesis and the associated NPQ were found to be stimulated in $p d x 1$, and during long-term exposure to high light, the steady-state level of zeaxanthin was higher in $p d x 1$ than in WT. Thus, the major antioxidant mechanisms involved in ${ }^{1} \mathrm{O}_{2}$ elimination in leaves did not appear to be reduced in $p d x 1$, supporting the notion that the reduced capacity of ${ }^{1} \mathrm{O}_{2}$ quenching was directly related to the low concentration of vitamin B6, rather than to a secondary effect of vitamin B6 deficiency on the level of other antioxidant mechanisms. In sterile growth conditions, roots of Arabidopsis seedlings deficient in vitamin B6 displayed significant changes in lipid constituent content, such as a strong increase in $\alpha$ tocopherol, supporting the idea that oxidative stress is involved in the inhibition of root growth [68].

Vitamin B6 deficiency induces chronic light stress in leaves Acclimation of WT Arabidopsis to high light induced marked changes in the protein composition of thylakoids. As previously reported [e.g. [70,71]], the most obvious modification was a decrease in the PSII antenna size, leading to a higher $\mathrm{Chl} a / \mathrm{Chl} b$ ratio. The abundance of all Lhcb proteins, except CP26 and to a lesser extent CP29, was decreased in high light. CP26 is supposed to constitute with CP29 an inner part of the antenna system that undergoes limited modifications with environmental conditions [71]. Interestingly, the loss of PSII antennae was observed in low light when thylakoids prepared from leaves of $p d x 1$ were compared with WT thylakoids and was strongly exacerbated when $p d x 1$ was exposed to high light $\left(1000 \mu \mathrm{mol} \mathrm{m} \mathrm{m}^{-2} \mathrm{~s}^{-1}\right)$. The gradient profile and characteristics of the photosynthetic complexes from low-lightgrown $p d x 1$ were very similar to that of high-light-acclimated WT thylakoids. Consistent with these observations the decreased Chl levels in $p d x 1$ versus WT was strongly dependent on light intensity: in very low light $(\sim 100 \mu \mathrm{mol}$ photons $\mathrm{m}^{-2} \mathrm{~s}^{-1}$ ), WT leaves and mutant leaves had very similar Chl $a / b$ ratio and total chlorophyll content whereas the Chl $a / b$ value differed drastically in high light. Thus, comparison of the photosynthetic complexes between $p d x 1$ and WT suggests that, for a given PFD, the mutant senses a higher level of light stress than WT. Since the ${ }^{1} \mathrm{O}_{2}$ level induced by light in $p d x 1$ was enhanced relative to WT, it is possible that the loss of Chl antennae represents a response to ${ }^{1} \mathrm{O}_{2}$ stress in the mutant. Although long-term acclimation of vascular plants to ${ }^{1} \mathrm{O}_{2}$ has not yet been investigated, ${ }^{1} \mathrm{O}_{2}$ is known to induce changes in gene expression. Particularly, the gene coding for the PSII antenna Lhcb2 has been shown to be strongly and specifically downregulated by ${ }^{1} \mathrm{O}_{2}$ [67]. In the green alga Chlamydomonas, the early phases of ${ }^{1} \mathrm{O}_{2}$-mediated photooxidative stress were associated with the repression of the Lhcbm 1 and Lhcbm 2 genes at the RNA level [72]. UV$B$ radiation, which is know to induce the production of ROS including ${ }^{1} \mathrm{O}_{2}$, has been shown to downregulate expression of several Lhcb genes [52]. Interestingly, these conditions also up-regulated the expression of a PDX1 homologue, PYROA [52]. Alternatively, the loss of PSII antennae could also result from the inhibition of Chl synthesis in the $p d x 1$ mutant. However, previous work on different transgenic plants have shown that a decreased availability of Chl induces a decrease in the amount of photosynthetic complexes embedded in the thylakoid membranes, but it does not change the PSII antenna size $[73,74]$.

\section{Conclusion}

The potential function of the vitamin B6 constituents as antioxidants has been reported in several in vitro studies in which yeast or animal cells were treated with different ROS [12-16]. There are also a few preliminary studies performed in vitro, that support the idea that vitamin B6 could fulfill a similar role in plant cells $[11,17,21]$. The present study of whole Arabidopsis plants provides the first evidences for an active and specific antioxidant role of vitamin B6 in planta. Vitamin B6 deficiency was associated with a marked decrease in the tolerance to photooxidative stress, which manifested itself as an increase in the ${ }^{1} \mathrm{O}_{2}$ level in high light and a marked enhancement in ${ }^{1} \mathrm{O}_{2}$ mediated lipid peroxidation. On the other hand, it is known that there are some redundancies between the antioxidant systems in chloroplasts, so that removing one antioxidant mechanism is generally compensated, at least partially, by an increase in other protections. This has been established in Arabidopsis and cyanobacteria for two classes of ${ }^{1} \mathrm{O}_{2}$ quenchers, the carotenoids and the tocopherols $[47,75]$. Similarly, removal of vitamin B6 from an Arabidopsis mutant deficient in both carotenoids and tocopherols resulted in an extreme sensitivity to high light stress. These result indicate that vitamin B6 may play a specific role in antioxidant defense that is not completey fulfilled by carotenoids or tocopherols. Consequently, 
vitamin $\mathrm{B} 6$ can be considered as a new member of the network of protective compounds involved in the management of ${ }^{1} \mathrm{O}_{2}$ in plants.

\section{Methods}

Plant material, growth conditions and treatments

Wild-type Arabidopsis thaliana (ecotype Col-0) and the $p d x 1.3$ (At5g01410) T-DNA line were grown in a phytotron under controlled conditions: PFD was 150-200 $\mu$ mol photons $\mathrm{m}^{-2} \mathrm{~s}^{-1}$, photoperiod $8 \mathrm{~h}$, air temperature $23 / 28^{\circ} \mathrm{C}$ (day/night) and relative air humidity $75 \%$. Most of the experiments were performed on plants aged 5 weeks. Light stress was imposed by transferring plants to a growth chamber at $6 / 12^{\circ} \mathrm{C}$ (day/night) under a PFD of $1500 \mu \mathrm{mol}$ photons $\mathrm{m}^{-2} \mathrm{~s}^{-1}$ and a photoperiod of $8 \mathrm{~h}$. In preliminary experiments where we checked a number of light/temperature conditions, we selected this stress condition that appeared to be the most suitable to discriminate between WT and $p d x 1$ in terms of photosensitivity. The $p d x 1$ mutant was crossed with the vte 1 npq1 double mutant (see [47]) to generate the triple mutant vte 1 npq1 $p d x 1$ deficient in vitamin E, zeaxanthin and vitamin B6. The triple mutant and the double/single mutants were exposed to light stress by transferring them to a PFD of $1000 \mu \mathrm{mol}$ photons $\mathrm{m}^{-2} \mathrm{~s}^{-1}$ at $10^{\circ} \mathrm{C}$.

Leaf discs of $1 \mathrm{~cm}$ in a diameter were treated with a solution of $3.5 \% \mathrm{H}_{2} \mathrm{O}_{2}, 50 \mu \mathrm{M}$ methylviologen or $0.5 \%$ eosin $\mathrm{Y}$, as previously described [31]. The infiltrated discs were exposed to white light of PFD $400 \mu \mathrm{mol}$ photons $\mathrm{m}^{-2} \mathrm{~s}^{-1}$ (for the eosin or methylviologen treatment) or $100 \mu \mathrm{mol}$ $\mathrm{m}^{-2} \mathrm{~s}^{-1}$ (for the $\mathrm{H}_{2} \mathrm{O}_{2}$ treatment). Attached leaves were slowly infiltrated with $100 \mu \mathrm{M}$ SOSG (Singlet Oxygen Sensor Green, Invitrogen) and/or vitamin B6 (1 mM pyridoxal) under pressure with a syringe. A 1-ml syringe, without needle and filled with the solution to be infiltrated, was pushed against the lower surface of the leaf, and the solution $(200 \mu \mathrm{l})$ was forced to enter inside of the leaf under pressure. Plants with SOSG-infiltrated leaves were kept in darkness for $1 \mathrm{~h}$ and then exposed for $40 \mathrm{~min}$ to white light of PFD $450 \mu \mathrm{mol}$ photons $\mathrm{m}^{-2} \mathrm{~s}^{-1}$. For high light treatment of leaf discs, the discs (diameter, $1 \mathrm{~cm}$ ) were exposed at constant temperature $\left(10^{\circ} \mathrm{C}\right)$ to white light (PFD, $1000 \mu \mathrm{mol}$ photons $\mathrm{m}^{-2} \mathrm{~s}^{-1}$ ), as previously described [47]. In some cases, leaf discs were preinfiltrated with $2 \mathrm{mM}$ vitamin B6 (pyridoxal) for $1 \mathrm{~h}$. PFDs were measured with a Li-Cor quantum meter (Li-185B/Li190SB).

\section{Chlorophylls, carotenoids and vitamin E}

One leaf disc (diameter, $1 \mathrm{~cm}$ ) was ground in $400 \mu \mathrm{l}$ of cold methanol. After filtration through a $0.45-\mu \mathrm{m}$ PTFE filter (Iso-Disc, SUPELCO), $80 \mu \mathrm{l}$ of the extract was immediately analyzed by HPLC, as previously described [47]. Pigments were detected at $445 \mathrm{~nm}$ and $\alpha$-tocopherol was detected by fluorescence $\left(\lambda_{\text {ex }}=295 \mathrm{~nm}, \lambda_{\text {em }}=340 \mathrm{~nm}\right)$. Running time was $22 \mathrm{~min}$, flow rate was $1.5 \mathrm{ml} . \mathrm{min}^{-1}$.

\section{Chlorophyll precursors}

Chlorophyll esters and (proto)chlorophyllide were quantitated using reverse phase HPLC analysis according to [76], except that detection was performed by absorbance at $430 \mathrm{~nm}$.

\section{Ascorbic Acid}

Ascorbate was analyzed by HPLC as described elsewhere [47]. Total ascorbate was measured by reducing dehydroascorbic acid to ascorbic acid with TCEP (Tris-carboxyethylphosphine). Three leaf discs of $1 \mathrm{~cm}$ in diameter (about $100 \mathrm{mg}$ ) were ground in $750 \mu \mathrm{L}$ of $0.1 \mathrm{M}$ metaphosphoric acid. Samples were filtered through a $0.2 \mu \mathrm{m}$ nylon membrane (Spin-X Costar). A $6 \mu \mathrm{L}$ sample was immediately injected, and $6 \mu \mathrm{L}$ were treated for $4 \mathrm{~h}$ with $10 \mathrm{mM}$ TCEP in darkness at $25^{\circ} \mathrm{C}$. Ascorbate was detected at $245 \mathrm{~nm}$ in sulphuric acid-acidified water ( $\mathrm{pH} 2.5$ ) with a retention time of $5 \mathrm{~min}$ under a flow of $0.65 \mathrm{~mL} \mathrm{~min}-1$.

\section{Lipid peroxidation analyses}

Lipids were extracted from $0.5 \mathrm{~g}$ frozen leaves by grinding with $2 \times 1 \mathrm{~mL}$ chloroform containing $1 \mathrm{mg} / \mathrm{mL}$ triphenyl phosphine and $0.05 \%(\mathrm{w} / \mathrm{v})$ butylated hydroxytoluene, with 15-hydroxy-11,13(Z, E)-eicosadienoic acid as internal standard. The organic phase was evaporated under a stream of $\mathrm{N}_{2}$. The residue was recovered in $1.25 \mathrm{~mL}$ ethanol and $1.25 \mathrm{~mL} 3.5 \mathrm{M} \mathrm{NaOH}$ and hydrolyzed at $80^{\circ} \mathrm{C}$ for $15 \mathrm{~min}$. After addition of $2.2 \mathrm{~mL} 1 \mathrm{M}$ citric acid, hydroxyl fatty acids were extracted with $2 \times 1 \mathrm{~mL}$ hexane/ether (50/ $50)$. An aliquot of the organic phase $(50 \mu \mathrm{l})$ was submitted to straight phase HPLC (Waters, Millipore, St Quentin-Yvelines, France) using a Zorbax rx-SIL column (4.6. $250 \mathrm{~mm}, 5 \mu \mathrm{m}$ particle size, Hewlett Packard, Les Ullis, France), isocratic elution with 70/30/0.25 (v/v/v) hexane/diethyl ether/acetic acid at a flow rate of $1.5 \mathrm{ml}$ $\min ^{-1}$, and UV detection at $234 \mathrm{~nm}$. ROS-induced lipid peroxidation was evaluated from the levels of the different hydroxyoctadecatrienoic acid (HOTE) isomers as previously described using 15-hydroxy-11,13(Z, E) eicosadienoic acid as internal standard [77]. LOX-induced lipid peroxidation was estimated from the level of 13-HOTE after substraction of racemic 13-HOTE (attributable to ROS-mediated lipid peroxidation), as explained in [77].

The distribution of hydroxy fatty acid isomers was analyzed by HPLC-electrospray ionization-MS/MS as detailed previously [42]. Aliquots from the hydroxyl fatty acid extracts were evaporated and recovered in aqueous $1 \mathrm{mM}$ ammonium acetate/acetronitrile (60/40, v/v) with $\left[{ }^{18} \mathrm{O}_{2}\right] 13$-HOTE used as internal standard. Hydroxy fatty acids were separated by HPLC and analyzed using a Waters Micromass Quatro premier triple quatrupole mass 
spectrometer in the negative electrospray ionization mode.

\section{Thermoluminescence and autoluminescence imaging}

Lipid peroxidation was measured in leaf discs by thermoluminescence using a custom-made apparatus that has been described previously [40]. The amplitude of the thermoluminescence band peaking at ca. $135^{\circ} \mathrm{C}$ was used as an index of lipid peroxidation $[40,78]$. The samples (2 leaf discs of $8 \mathrm{~mm}$ in diameter) were slowly heated from $25^{\circ} \mathrm{C}$ to $150^{\circ} \mathrm{C}$ at a rate of $6^{\circ} \mathrm{C} \mathrm{min}^{-1}$. Photon emission associated with lipid peroxidation was also imaged at room temperature using a highly sensitive charge coupled device (CCD) camera (VersArray LN/CCD 1340-1300B, Roper Scientific), with a liquid $\mathrm{N}_{2}$ cooled sensor to enable measurement of faint light by signal integration [34]. Treated plants were dark-adapted for $2 \mathrm{~h}$ before imaging, to allow chlorophyll luminescence to fade away. Acquisition time was $20 \mathrm{~min}$. Full resolution of the CCD is 1300 $\times 1340$ pixels. On-CCD binning of $2 \times 2$ pixels was used to increase detection sensitivity, so that the resulting resolution was $650 \times 670$ pixels.

\section{Photosynthetic electron transport}

$\mathrm{Chl}$ fluorescence from attached leaves was measured in air at room temperature with a PAM-2000 fluorometer (Walz) [47]. The quantum yield of PSII photochemistry was calculated in white light as $\Delta \mathrm{F} / \mathrm{Fm}$ ', where $\Delta \mathrm{F}$ is the difference (Fm'-Fs) between the maximal fluorescence level Fm' (measured with a 800-ms pulse of saturating light) and Fs, the steady-state fluorescence level. White light was produced by a Schott KL1500 light source. NPQ was calculated as (Fm/Fm')-1 where Fm is the maximal fluorescence level in the dark [47].

$\mathrm{O}_{2}$ exchange by leaf discs was measured in a Clark-type $\mathrm{O}_{2}$ electrode (Hansatech LD2/2) under $\mathrm{CO}_{2}$ saturating conditions. $\mathrm{CO}_{2}$ was generated in the cell with a carbonate/ bicarbonate buffer. White light was produced by a Hansatech LS2 light source combined with neutral density filters.

\section{Membrane preparation and solubilisation}

Arabidopsis leaves were shortly grinded in a solution containing $20 \mathrm{mM}$ Tricine $\mathrm{KOH} \mathrm{pH} 7.8,0.4 \mathrm{M} \mathrm{NaCl}, 2 \mathrm{mM}$ $\mathrm{MgCl}_{2}$ and the protease inhibitors $0.2 \mathrm{mM}$ benzamidine, $1 \mathrm{mM}$-aminocaproic acid. The solution was filtered through miracloth tissue and centrifuged $10 \mathrm{~min}$ at 1400 g. The pellet was resuspended in a solution containing 20 $\mathrm{mM}$ Tricine $\mathrm{KOH} \mathrm{pH} 7.8,0.15 \mathrm{M} \mathrm{NaCl}, 5 \mathrm{mM} \mathrm{MgCl}_{2}$ and protease inhibitors as before and then centrifuged $10 \mathrm{~min}$ at $4000 \mathrm{~g}$. The pellet was resuspended in $20 \mathrm{mM}$ Hepes 7.5, $15 \mathrm{mM} \mathrm{NaCl}, 5 \mathrm{mM} \mathrm{MgCl}$ and centrifuged again 10 min at $6000 \mathrm{~g}$ and stocked in $20 \mathrm{mM}$ Hepes 7.5, $0.4 \mathrm{M}$ Sorbitol, $15 \mathrm{mM} \mathrm{NaCl}, 5 \mathrm{mM} \mathrm{MgCl}_{2}$.
Membranes corresponding to $150 \mu \mathrm{g}$ Chls were washed once with $5 \mathrm{mM}$ EDTA, $10 \mathrm{mM}$ Hepes $\mathrm{pH} 7.5$, resuspended at $1 \mathrm{mg} / \mathrm{ml}$ Chls in $10 \mathrm{mM}$ Hepes $\mathrm{pH} 7.5$ and then solubilized at $0.5 \mathrm{mg} / \mathrm{ml}$ Chls by adding an equal volume of dodecyl- $\alpha$-D-maltoside solution to have at a final detergent concentration of $0.8 \%$ or $1.2 \%$ and vortexing for a few seconds. The solubilised samples were centrifuged at $15.000 \times \mathrm{g}$ for $10 \mathrm{~min}$ to eliminate unsolubilised material and then fractionated by ultracentrifugation in a sucrose gradient $\left(20 \mathrm{~h}, 288.000 \times \mathrm{g}, 4^{\circ} \mathrm{C}\right)$. The gradient was formed directly in the tube by freezing at $-80^{\circ} \mathrm{C}$ and thawing at $4^{\circ} \mathrm{C}$ a $0.5 \mathrm{M}$ sucrose solution containing $0.06 \% \alpha$ DM and $10 \mathrm{mM}$ Hepes $\mathrm{pH} 7.5$.

Chlorophylls and carotenoids were extracted in acetone ( $80 \%$ final concentration buffered with $\mathrm{Na}_{2} \mathrm{CO}_{3}$ ) and measured by fitting of the absorption spectrum of acetone extracts [79].

\section{SDS-Page}

Electrophoresis were performed using the Tris-Tricine system at $14 \%$ acrylamide concentration [80] or the Laemmli system [81] with the modification as in [82].

\section{Vitamin B6}

HPLC measurements of nonphosphorylated vitamin B6 components were carried out on leaves or isolated chloroplasts as described elsewhere [19,20]. Vitamin B6 was extracted from approximately $10 \mathrm{~g}$ of leaves (fresh weight). Intact chloroplasts were prepared from about $100 \mathrm{~g}$ of tobacco leaves, as described previously [83].

\section{Abbreviations}

Chl: chlorophyll; Lhcb: Light harvesting complex of PSII; PS: photosystem; PFD: photon flux density; ${ }^{1} \mathrm{O}_{2}$ : singlet oxygen; WT: wild type; PChlide and Chlide: protochlorophyllide and chlorophyllide; ROS: reactive oxygen species; HOTE: hydroxy octadecatrienoic acid; SOSG: singlet oxygen sensor green; NPQ: nonphotochemical quenching.

\section{Authors' contributions}

$\mathrm{MH}$ designed and performed the experiments. BK and CT performed HPLC analyses of hydroxy fatty acids. AS and DR measured vitamin B6 concentration in leaves and chloroplasts. FF analyzed Chl precursors. SC performed the characterization of the photosynthetic complexes. $\mathrm{MH}$ wrote the manuscript. All authors read and approved the final version of the manuscript. 


\section{Additional material}

\section{Additional file 1}

Effects of the pdx 1 mutation on growth of Arabidopsis plants on soil A) Shoot growth as measured by the rosette diameter (in cm), B) Roots after 4-week growth. Root length and dry weight are expressed in $\mathrm{cm}$ and mg dry weight (D.W.) per plant, respectively.

Click here for file

[http://www.biomedcentral.com/content/supplementary/14712229-9-130-S1.ppt]

\section{Additional file 2}

Oxidative stress in Arabidopsis leaf discs (WT and $\mathrm{pdx} 1$ ) exposed to hydrogen peroxide (3.5\%) or to the superoxide-generating methylviologen herbicide $(50 \mu \mathrm{M})$. A) Autoluminescence imaging of leaf discs exposed for 0, 5, 24 and $66 \mathrm{~h}$ to hydrogen peroxide in low light $(100 \mu \mathrm{mol}$ $\left.m^{-2} s^{-1}\right), B$ ) Autoluminescence intensity of leaf discs exposed for 0 or $24 \mathrm{~h}$ to hydrogen peroxide in low light (data are mean values of 10 measurements $+S D), C)$ Autoluminescence imaging of leaf discs exposed to methylviologen in the light (PFD, $400 \mu \mathrm{mol}$ photons $\mathrm{m}^{-2} \mathrm{~s}^{-1}$ ) for $0,2.5,5$ and $7 \mathrm{~h} . \mathrm{D})$ Autoluminescence intensity of leaf discs exposed for $5 \mathrm{~h}$ to methylviologen in the light. Data are mean values of 10 measurements $+S D$. Click here for file

[http://www.biomedcentral.com/content/supplementary/14712229-9-130-S2.ppt]

\section{Additional file 3}

Absorption spectrum of the pigments extracted from A) the B2 band, $B$ ) the $B 3$ band and C) the B6 band of the sucrose gradients (see Fig. 10A). Pigments were extracted in acetone as explained elsewhere [79]. Click here for file

[http://www.biomedcentral.com/content/supplementary/14712229-9-130-S3.doc]

\section{Additional file 4}

Nonphosphorylated vitamin $B 6$ concentration (normalized to the Chl content) in tobacco leaves and in intact chloroplasts prepared from tobacco leaves. $P N=$ Pyridoxine $P M=$ Pyridoxamine.

Click here for file

[http://www.biomedcentral.com/content/supplementary/14712229-9-130-S4.ppt]

\section{Acknowledgements}

We would like to thank Dr. L. Xiong (St Louis, USA) for providing $p d x I$ seeds, Dr. M. Mueller (Wurzburg, Germany) for help with HPLC-MS/MS analyses, Simona Vesa (CEA/Cadarache) for RT-PCR analyses of Arabidopsis mutants, Pascal Rey (CEA/Cadarache) for useful discussions, and Ben Field (University of Marseille) for reading the manuscript and improving the English. Many thanks also to the 'Groupe de Recherche Appliquée en Phytotechnie' (CEA/Cadarache) for help in growing plants under light stress conditions.

\section{References}

I. Drewke C, Leistner E: Biosynthesis of vitamin B6 and structur ally related derivatives. Vitam Horm 200I, 6 I: I $21-155$.

2. Roje S: Vitamin B biosynthesis in plants. Phytochemistry 2007 68:1904-1921.
3. Mooney S, Leuendorf JE, Hendrickson C, Hellmann H: Vitamin B6: a long known compound of surprising complexity. Molecules 2009, | 4:329-35|.

4. Tambasco-Studart M, Titiz O, Raschle T, Forster G, Amrhein N, Fitzpatrick TB: Vitamin B6 biosynthesis in higher plants. Proc Natl Acad Sci USA 2005, I 02: | 3687-13692.

5. Tambasco-Studart M, Tews I, Amrhein N, Fitzpatrick TB: Functiona analysis of PDX2 from Arabidopsis, a glutaminase involved in vitamin B6 biosynthesis. Plant Physiol 2007, I44:915-925.

6. John RA: Pyridoxal phosphate-dependent enzymes. Biochim Biophys Acta 1995, I 248:8I-96.

7. Percudani R, Peracchi A: A genomic overview of pyridoxal-phosphate-dependent enzymes. EMBO Rep 2003, 4:850-854.

8. Jenns AE, Scott DL, Bowden EF, Daub ME: Isolation of mutants of the fungus Cercospora nicotianae altered in their response to singlet-oxygen-generating photosensitizers. Photochem Photobiol 1995, 6 I:488-493.

9. Ehrenshaft M, Bilski P, Li MY, Chignell CF, Daub ME: A highly conserved sequence is a novel gene involved in de novo vitamin B6 biosynthesis. Proc Natl Acad Sci USA 1999, 96:9374-9378.

10. Bilski P, Li MY, Ehrenshaft M, Daub ME, Chignell CF: Vitamin B6 (pyridoxine) and its derivatives are efficient singlet oxygen quenchers and potential fungal antioxidants. Photochem Photobiol 2000, 7I:129-134.

II. Denslow SA, Walls AA, Daub ME: Regulation of biosynthetic genes and antioxidant properties of vitamin B6 vitamers during plant defense responses. Physiol Mol Plant Pathol 2005, 66:244-255

12. Jain SK, Lim G: Pyridoxine and pyridoxamine inhibits superoxide radicals and prevents lipid peroxidation, protein glycosylation, and $\left(\mathrm{Na}^{+}+\mathrm{K}^{+}\right)$-ATPase activity reduction in high glucose-treated human erythrocytes. Free Rad Biol Med 200I, 30:232-237

13. Stocker P, Lesgards J-F, Vidal N, Chalier F, Prost M: ESR study of a biological assay on whole blood: antioxidant efficiency of various vitamins. Biochim Biophys Acta 2003, I 62 I: I-8.

14. Kannan $\mathrm{K}$, Jain SK: Effect of vitamin $\mathbf{B}_{6}$ on oxygen radicals, mitochondrial membrane potential, and lipid peroxidation in $\mathbf{H}_{2} \mathbf{O}_{2}$-treated $\mathbf{U 9 3 7}$ monocytes. Free Rad Biol Med 2004 , 36:423-428.

I5. Chumnantana R, Yokochi N, Yagi T: Vitamin B6 compounds prevent the death of yeast cells due to menadione, a reactive oxygen generator. Biochim Biophys Acta 2005, I 722:84-9|

16. Endo N, Nishiyama K, Okabe M, Matsumoto M, Kanouchi H, Oka T: Vitamin $B_{6}$ suppresses apoptosis of NM-I bovine endothelial cells induced by homocysteine and copper. Biochim Biophys Acta 2007, I770:57|-577

17. Danon A, Miersch O, Felix G, op den Camp RGL, Apel K: Concurrent activation of cell death-regulating signalling pathways by singlet oxygen in Arabidopsis thaliana. Plant J 2005, 41 :68-80.

18. Titiz O, Tambasco-Studart M, Warzych E, Apel K, Amrhein N, Lalo C, Fitzpatrick TB: PDXI is essential for vitamin B6 biosynthesis, development and stress tolerance in Arabidopsis. Plant J 2006, 48:933-946.

19. Wagner S, Bernhardt A, Leuendorf JE, Drewke C, Lytovchenko A, Mujahed N, Gurgui C, Frommer WB, Leistner E, Fernie AR, Hellmann $\mathrm{H}$ : Analysis of the Arabidopsis rsr4-I/pdxI-3 mutant reveals the critical function of the PDXI protein family in metabolism, development, and vitamin B6 biosynthesis. Plant Cell 2006, I 8: I722-I735.

20. Leuendorf JE, Genau A, Szewczyk A, Mooney S, Drewke C, Leistner $\mathrm{E}$, Hellmann $\mathrm{H}$ : The Pdx I family is structurally and functionally conserved between Arabidopsis thaliana and Ginkgo biloba. FEBS J 2008, 275:960-969.

21. Chen $\mathrm{H}$, Xiong L: Pyridoxine is required for post-embryonic root development and tolerance to osmotic and oxidative stress. Plant ] 2005, 44:396-408.

22. Chen $\mathrm{H}$, Xiong $\mathrm{L}$ : The short-rooted vitamin B6-deficient mutant pdxl has impaired local auxin biosynthesis. Planta 2009, 229:|303-|3|0.

23. Rüdiger W, Benz J, Guthoff C: Detection and partial characterization of activity of chlorophyll synthetase in etioplast membranes. Eur J Biochem 1980, 109:193-200.

24. Soll J, Schultz G: Phytol synthesis from geranylgeraniol in spinach chloroplasts. Biochem Biophys Res Commun I98I, 99:907-912. 
25. Soll J, Schultz G, Rüdiger W, Benz J: Hydrogenation of geranylgeraniol: Two pathways exist in spinach chloroplasts. Plant Physiol 1983, 7 I:849-854.

26. Keller Y, Bouvier F, D'Harlingue A, Camara B: Metabolic compartmentation of plastid prenyllipid biosynthesis -- evidence for the involvement of a multifunctional geranylgeranyl reductase. Eur J Biochem 1998, 25 I:4I3-4I7.

27. Wu Z, Zhang X, He B, Diao L, Sheng S, Wang J, Guo X, Su N, Wang L, Jiang L, Wang C, Zhai H, Wan J: A chlorophyll-deficient rice mutant with impaired chlorophyllide esterification in chlorophyll biosynthesis. Plant Physiol 2007, I 45:29-40.

28. Horton P, Ruban AV, Walters RG: Regulation of light harvesting in green plants. Annu Rev Plant Physiol Plant Mol Biol 1996 47:655-684.

29. Holt NE, Fleming GR, Niyogi KK: Toward an understanding of the mechanism of nonphotochemical quenching in green plants. Biochemistry 2004, 43:828I-8289.

30. Knox JP, Dodge AD: The photodynamic action of eosin, a singlet oxygen generator. Some effects on leaf tissues of Pisum sativum L. Planta 1985, I 64:22-29.

31. Havaux M, Bonfils J-P, Lütz C, Niyogi KK: Photodamage of the photosynthetic apparatus and its dependence on the leaf developmental stage in the npq I Arabidopsis mutant in the xanthophyll cycle enzyme violaxanthin de-epoxidase. Plant Physiol 2000, I 24:273-284.

32. Devaraj $\mathrm{B}$, Usa $\mathrm{M}$, Inaba $\mathrm{H}$ : Biophotons: ultraweak light emission from living systems. Curr Opin Solid State Mat Sci 1997, 2: I88- 193.

33. Vavilin DV, Ducruet J-M: The origin of $1 / 5-130^{\circ} \mathrm{C}$ thermoluminescence bands in chlorophyll containing material. Photochem Photobiol 1998, 68:191-198.

34. Havaux M, Triantaphylidès C, Genty B: Autoluminescence imaging: a non-invasive tool for imaging oxidative stress. Trends Plant Sci 2006, I I:480-484

35. Flor-Henry M, Mccabe TC, de Bruxelles GL, Roberts MR: Use of a highly sensitive two-dimensional luminescence imaging system to monitor endogenous bioluminescence in plant leaves. BMC Plant Biol 2004, 4:19.

36. Johnson MP, Havaux M, Triantaphylidès $C$, Ksas B, Pascal AA, Robert $B$, Davison PA, Ruban AV, Horton P: Elevated zeaxanthin bound to oligomeric LHCII enhances the resistance of Arabidopsis to photooxidative stress by a lipid-protective, antioxidant mechanism. J Biol Chem 2007, 282:22605-226I8.

37. Collin VC, Eymery F, Genty B, Rey P, Havaux M: Vitamin E is essential for the tolerance of Arabidopsis thaliana to metalinduced oxidative stress. Plant Cell Environ 2007, 3 I:244-257.

38. Kobayashi $M$, Takeda $M$, Ito $K$, Kato $H$, Inaba $\mathrm{H}$ : In vivo imaging of spontaneous ultraweak photon emission from a rat's brain correlated with cerebral energy metabolism and oxidative stress. Neurosci Res 1999, 34:103-II3.

39. Van Wijk R, Kobayashi M, van Wijk EP: Anatomic characterization of human ultra-weak photon emission with a moveable photomultiplier and CCD imaging. J Photochem Photobiol B:Biol 2006, 83:69-76.

40. Havaux M: Spontaneous and thermoinduced photon emission: new methods to detect and quantify oxidative stress in plants. Trends Plant Sci 2003, 8:409-4I3.

4I. Muller-Moulé P, Havaux M, Niyogi KK: Zeaxanthin deficiency enhances the high light sensitivity of an ascorbate-deficient mutant of Arabidopsis. Plant Physiol 2003, I 33:748-760.

42. Triantaphylidès C, Krischke M, Hoeberichts FA, Ksas B, Gresser G, Havaux M, Van Breusegem F, Mueller MJ: Singlet oxygen is the major reactive oxygen species involved in photooxidative damage to plants. Plant Physiol 2008, I48:960-968

43. Wise RR: Chilling-enhanced photooxidation: the production, action and study of reactive oxygen species produced during chilling in the light. Photosynth Res 1995, 45:79-97.

44. Carlsson AS, Wallin G, Sandelius AS: Species- and age-dependent sensitivity to ozone in young plants of pea, wheat and spinach: effects in acyl lipid and pigment content and metabolism. Physiol Plant 1996, 98:27I-280.

45. Mueller MJ, Mène-Saffrané L, Grun C, Karg K, Farmer EE: Oxylipin analysis methods. Plant J 2006, 45:472-489.

46. Flors C, Fryer MJ, Waring J, Reeder B, Bechtold U, Mullineaux PM, Nonell S, Wilson MT, Baker NR: Imaging the production of singlet oxygen in vivo using a new fluorescent sensor, singlet oxygen sensor green. J Exp Bot 2006, 57:1725-1734.
47. Havaux M, Eymery F, Porfirova S, Rey P, Dörmann P: Vitamin E protects against photoinhibition and photooxidative stress in Arabidopsis thaliana. Plant Cell 2005, I 7:345I-3469.

48. Triantaphylidès $C$, Havaux M: Singlet oxygen in plants: Produc tion, detoxification and signalling. Trends Plant Sci 2009 , 14:219-228.

49. Morosinotto T, Caffarri S, Dall'Osto L, Bassi R: Mechanistic aspects of the xanthophyll dynamics in higher plant thylakoids. Physiol Plant 2003, I I 9:347-354.

50. Caffarri S, Frigerio S, Olivieri E, Righetti PG, Bassi R: Differential accumulation of lhcb gene products in thylakoid membranes of Zea mays plants grown under contrasting light and temperature conditions. Proteomics 2005, 5:758-768.

5I. Hutin C, Havaux M, Carde JP, Kloppstech K, Meierhoff K, Hoffman N, Nussaume L: Double mutation cpSRP43-/cpSRP54- is necessary to abolish the cPSRP pathway required for targeting of the light-harvesting chlorophyll proteins. Plant J 2002, 29:53|-543.

52. Brosché M, Schuler MA, Kalbina I, Connor L, Strid A: Gene regulation by low level UV-B radiation: identification by DNA array analysis. Photochem Photobiol Sci 2002, I:656-664.

53. Krieger-Liszkay A, Fufezan C, Trebst A: Singlet oxygen production in photosystem II and related protection mechanisms. Photosynth Res 2008, 98:55I-564.

54. Winter $H$, Robinson DG, Heldt HW: Subcellular volumes and metabolite concentrations in spinach leaves. Planta 1994, 193:530-535

55. Sang Y, Barbosa JM, Wu H, Locy RD, Singh NK: Identification of a pyridoxine (pyridoxamine) 5'-phosphate oxidase from Arabidopsis thaliana. FEBS Lett 2007, 581 : 344-348.

56. Fischer BB, Krieger-Liszkay A, Hideg E, Snyrychová I, Wiesendanger $M$, Eggen RI: Role of singlet oxygen in chloroplast to nucleus retrograde signaling in Chlamydomonas reinhardtii. FEBS Lett 2007, 58 I:5555-5560.

57. Esterbauer $\mathrm{H}$, Schaur RJ, Zollner H: Chemistry and biochemistry of 4-hydroxynonenal, malonaldehyde and related aldehydes. Free Rad Biol Med 1991, I I:81-128.

58. Farmer EE, Davoine C: Reactive electrophile species. Curr Opin Plant Biol 2007, 10:380-386.

59. Pamplona R: Membrane phospholipids, lipoxidative damage and molecular integrity: A causal role in aging and longevity. Biochim Biophys Acta 2008, I 777: I 249-1 262.

60. Metz TO, Alderson NL, Chachich ME, Thorpe SR: Pyridoxamine traps intermediates in lipid peroxidation reactions in vivo. Biol Chem 2003, 278:42012-42019.

6I. Kang Z, Li H, Li G, Yin D: Reaction of pyridoxamine with malondialdehyde: mechanism of inhibition of formation of advanced lipoxidation end-products. Amino Acids 2006 30:55-6I

62. Voziyan PA, Hudson BG: Pyridoxamine: the many virtues of a Maillard reaction inhibitor. Ann NY Acad Sci 2005, I 043:807-8I6.

63. Jain AK, Lim G, Langford M, Jain SK: Effect of high-glucose levels on protein oxidation in cultured lens cells, and in crystalline and albumin solution and its inhibition by vitamin B6 and $\mathbf{N}$. acetylcysteine: its possible relevance to cataract formation in diabetes. Free Radic Biol Med 2002, 33:1615-1621.

64. Mano J, Belles-Boix E, Babiychuk E, Inez D, Torii Y, Hiraoka E, Takimoto K, Slooten L, Asada K, Kushnir S: Protection against photooxidative injury of tobacco leaves by 2 -alkenal reductase. Detoxification of lipid-peroxide reactive carbonyls. Plant Physiol 2005, I39: I773-I783.

65. Van Oosterom EJ, Acevedo E: Adaptation of barley (Hordeum vulgare L.) to harsh Mediterranean environments. I. Morphological traits. Euphytica 1992, 62:1-14

66. Kyparissis A, Petropoulou Y, Manetas Y: Summer survival of leaves in a soft-leaved shrub (Phlomis fruticosa L., Labiatae) under Mediterranean field conditions: avoidance of photoinhibitory damage through decreased chlorophyll contents. J Exp Bot 1995, 46:1825-1831.

67. Op den Camp RGL, Przybyla D, Ochsenbein C, Laloi C, Kim C Danon A, Wagner D, Hideg E, Göbel C, Feussner I, Nater M, Apel K: Rapid induction of distinct stress responses after release of singlet oxygen in Arabidopsis. Plant Cell 2003, 15:2320-2332.

68. Lytovchenko A, Bellegia R, Schauer N, Isaacson T, Leuendorf JE, Hellmann H, Rose JKC, Fernie AR: Application of GC-MS for the 
detection of lipophilic compounds in diverse plant tissues. BMC Plant Methods 2009, 5:4.

69. Havaux M, Dall'Osto L, Bassi R: Zeaxanthin has enhanced antioxidant capacity with respect to all other xanthophylls in Arabidopsis leaves and functions independent of binding to PSII antennae. Plant Physiol 2007, I 45: I 506-1520.

70. Bailey S, Walters RG, Jansson S, Horton P: Acclimation of Arabidopsis thaliana to the light environment: the existence of separate low light and high light responses. Planta 200I, 213:794-80I.

71. Ballotari M, Dall'Osto L, Morosinotto T, Bassi R: Contrasting behaviour of higher plant photosystem I and II antennae systems during acclimation. J Biol Chem 2007, 282:8947-8958.

72. Ledford HK, Chin BL, Niyogi KK: Acclimation to singlet oxygen stress in Chlamydomonas reinhardtii. Eukaryot Cell 2007, 6:919-930.

73. Härtel H, Kruse E, Grimm B: Restriction of chlorophyll synthesis due to expression glutamate I-semialdehyde aminotransferase antisense RNA does not reduce the light-harvesting antenna size in tobacco. Plant Physiol | 997, I I 3: I I | 3- I 24.

74. Tzvetkova-Chevolleau T, Franck F, Alawady AE, Dall'Osto L, Carrière F, Bassi R, Grimm B, Nussaume L, Havaux M: The light stressinduced protein ELIP2 is a regulator of chlorophyll synthesis in Arabidopsis thaliana. Plant J 2007, 50:795-809.

75. Maeda H, Sakuragi $Y$, Bryant DA, DellaPenna D: Tocopherols protect Synechocystis sp. Strain PCC 6803 from lipid peroxidation. Plant Physiol 2005, I 38: | 422- 1435.

76. Böddi $B$, Loudèche R, Franck F: Delayed chlorophyll accumulation and pigment photodestruction in the epicotyls of darkgrown pea (Pisum sativum). Physiol Plant 2005, I 25:365-372.

77. Montillet JL, Cacas JL, Garnier L, Montané MH, Douki T, Bessoule J], Polkowska-Kowalczyk L, Maciejewska U, Agnel JP, Vial A, Triantaphylidès C: The upstream oxylipin profile of Arabidopsis thaliana: a tool to scan for oxidative stress. Plant J 2004 , 40:439-45।.

78. Ducruet JM: Chlorophyll thermoluminescence of leaf discs: simple instruments and progress in signal interpretation open the way to new ecophysiological indicators. J Exp Bot 2003, 54:2419-2430.

79. Croce R, Canino G, Ros F, Bassi R: Chromophore organization in the higher-plant photosystem II antenna protein CP26. Biochemistry 2002, 41:7334-7343.

80. Schagger H: Tricine-SDS-PAGE. Nat Protoc 2006, I:|6-22.

81. Laemmli UK: Cleavage of structural proteins during the assembly of the head of bacteriophage T4. Nature 1970, 227:680-685.

82. Ballottari M, Govoni C, Caffarri S, Morosinotto T: Stoichiometry of $\mathrm{LHCl}$ antenna polypeptides and characterization of gap and linker pigments in higher plants Photosystem I. Eur J Biochem 2004, 27 1:4659-4665.

83. Rumeau D, Cuiné S, Fina L, Gault N, Nicole M, Peltier G: Subcellular distribution of carbonic anhydrase in Solanum tuberosum $L$. leaves. Planta 1996, 199:79-88.

84. Ducruet JM, Vavilin D: Experimental conditions for using high temperature chlorophyll thermoluminescence as an indicator of oxidative stress. Proceedings of the winter meeting of the Society of Free Radical Research, December 1998, Granada, Spain 1998.

85. Bassi R, Dainese P: A supramolecular light-harvesting complex from chloroplast photosystem-II membranes. Eur J Biochem 1992, 204:317-326.

86. Boekema EJ, Jensen PE, Schlodder E, van Breemen JF, van Roon $\mathrm{H}$, Scheller HV, Dekker JP: Green plant photosystem I binds lightharvesting complex I on one side of the complex. Biochemistry 200I, 40:1029-1036

87. Wientjes E, Oostergetel GT, Jansson S, Boekema EJ, Croce R: The role of Lhca complexes in the supramolecular organization of higher plant photosystem I. J Biol Chem 2009, 284:7803-78I0.

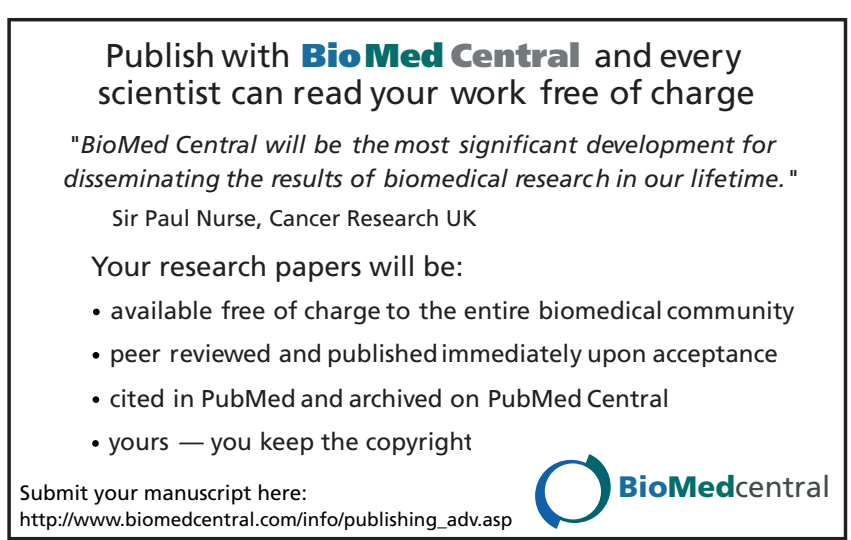

Page 22 of 22

(page number not for citation purposes) 